\title{
A Novel Integrated Fuzzy-Rough MCDM Model for Evaluation of Companies for Transport of Dangerous Goods
}

\author{
Nikolina Vojinović, ${ }^{1}$ Siniša Sremac $\mathbb{D}^{2},{ }^{2}$ and Dragan Zlatanović ${ }^{3}$ \\ ${ }^{1}$ Faculty of Law, University of Kragujevac, Jovana Cvijića 1, Kragujevac 34000, Serbia \\ ${ }^{2}$ University of Novi Sad, Faculty of Technical Sciences, Trg Dositeja Obradovića 6, Novi Sad 21000, Serbia \\ ${ }^{3}$ Innovation Centre, Faculty of Mechanical Engineering, University of Belgrade, Kraljice Marije 16, Belgrade 11000, Serbia
}

Correspondence should be addressed to Siniša Sremac; sremacs@uns.ac.rs

Received 28 October 2021; Revised 22 November 2021; Accepted 2 December 2021; Published 28 December 2021

Academic Editor: Borna Abramović

Copyright (@) 2021 Nikolina Vojinović et al. This is an open access article distributed under the Creative Commons Attribution License, which permits unrestricted use, distribution, and reproduction in any medium, provided the original work is properly cited.

\begin{abstract}
The organization and execution of the transport of dangerous goods is conditioned by a series of legal, technical, technological, safety, and engineering requirements, which must be met. In this way, a complex system is created which has a large number of participants and in which optimization should be performed at each stage from all the above aspects. The main goal of this paper is to create a novel Fuzzy-Rough MCDM (Multiple-Criteria Decision-Making) for the evaluation of companies engaged in the transport of dangerous goods. A group decision-making model was created to evaluate 11 transport companies based on nine legal, technical, technological criteria. The improved fuzzy stepwise weight assessment ratio analysis (IMF SWARA) method was used to calculate the criterion weights, while transport companies were ranked based on Rough Measurement Alternatives and Ranking according to the COmpromise Solution (R-MARCOS). The integration of these methods into a single model that combines two theories of uncertainty, fuzzy and rough, was performed for the first time in this study, which represents a significant contribution. The results show that the most significant criteria are as follows: dangerous goods are classified and permitted under ADR (Agreement Concerning the International Carriage of Dangerous Goods by Road), the prescribed documents are in the transport unit, and the equipment is in the transport unit. When it comes to the evaluation results of companies, it can be noticed that A1 and A4 show the best performance, while A8 and A9 are in the last position. In order to test the stability of the model developed, sensitivity analysis, comparative analysis, and the influence of the dynamic formation of the initial matrix were created.
\end{abstract}

\section{Introduction}

The organization of transport of dangerous goods is a technologically complex and demanding task. Standards and conditions that must be met by all participants, adequate infrastructure, and fixed assets (packaging, mobile pressure equipment, tanks, vehicles, tank cars, and ships) exceed the set of requirements for the transport of other types of goods. Generations of experts in various fields, primarily chemists and engineers of all necessary profiles, have permanently developed technical-technological systems for the safe transport of dangerous goods, and it is one of the most normatively regulated areas at the international and national level. Hazardous substances are substances or mixtures that with physical and chemical properties or reactions (explosiveness, flammability, toxicity, radiation hazard, corrosivity, and reactivity in general) during production, transport, storage, handling, and use can endanger human health and life, pollute the environment, and cause damage to material goods $[1,2]$. Also, the term "dangerous substance" refers to the factory declared physical-chemical characteristics of a substance determined based on the recognized and corresponding criteria [3]. Transport is the most technologically demanding and complex service in the supply chain of dangerous goods. For all modes of transport, especially road, rail, and water, all activities related to the transport of dangerous goods (storage, transhipment, etc.) will continue to grow, which may pose an additional risk not 
only for the participants themselves but also for the immediate environment $[4,5]$. The impact of dangerous goods on the environment is present through many primary areas, including mining [6], which can cause great risks in integration with their activities and handling of hazardous substances. Taking this into account, it is necessary to create decision models which can ensure sustainable development [7]. Transport of dangerous goods occupies a significant place in the total turnover of goods and represents a highrisk and at the same time necessary economic activity in everyday life. This is happening both globally and locally. The transport of dangerous goods must be organized according to rules that minimize the possibility of an accident or exceptional occurrence, that is, reducing the consequences of such events to a minimum. The organization of transport of dangerous goods is a global issue that is attracting increasing attention, primarily due to high potential risks, increased volume of transport, and the number of substances classified as dangerous, as well as specific challenges in the organization of transport. It greatly influences the creation of a complex system that reflects all aspects of engineering and other related fields.

In accordance with that and the socially responsible behavior in the field of reducing potential risks from accident situations, the subject of this study is the analysis of the current state of transport of dangerous goods in the territory of the Republic of Serbia and other related logistics activities. The motive for conducting such a study can be reflected in the importance of the field of research, which causally affects the social, economic, and environmental aspects of each individual. Evaluating the transport of dangerous goods is rare, so this is another motivation for performing such research. The main goal of the study is to determine the extent to which regulations and all requirements for successful transport of dangerous goods are met through the innovative creation of the Fuzzy-Rough MCDM model that will be used for comprehensive evaluation of the performance of transport companies.

In order to address this complex issue, this study aims to give concrete answers to three fundamental questions: (RQ1) Can sustainable and efficient processes be carried out in the field of transport of dangerous goods? (RQ2) Are there any differences in the evaluation of companies for transport of dangerous goods compared to other common transportation companies? (RQ3) Can the integrated IMF SWARA-Rough MARCOS model be useful for ranking companies for transport of dangerous goods?

This is primarily important because of the increasing pressure that all companies for the transport of dangerous goods have, related to the application of regulative and environmental standards and social responsibility. These two elements have become prerequisites for the efficient business of companies for transport of dangerous goods and constantly progress. Taking into account all previously mentioned, the contribution of this study can be manifested through the following:

(1) Innovative creation of the Fuzzy-Rough MCDM model that will be used for comprehensive evaluation of the performance of transport companies, enriching the whole MCDM field through forming the novel integrated model that can help decision-makers in evaluating and solving different problems.

(2) Contribution to the Prospective Multiple Attribute Decision-Making $[8,9]$ and creation of a novel integrated fuzzy-rough model based on hierarchical and methodological procedures for evaluating companies for transport of dangerous goods.

The rest of the study is conceived through the following sections. Section 2 presents the requirements and regulations for the transport of dangerous goods. The focus is on a set of regulations that must be complied with, at both the national and international levels, in order to be able to transport dangerous goods. Section 3 describes in detail the methodology developed and applied. Main operations with rough numbers, fuzzy numbers, Bonferroni aggregator, and steps of improved fuzzy SWARA and Rough MARCOS methods are shown. Section 4 provides a case study with a detailed description of the criteria. Then, an example of calculation for all steps of the methodology is presented so that the research can be reproduced in an easier way. Section 5 presents a stability test of the developed model by changing the size of the initial matrix and changing the significance of the three most significant criteria and a comparative analysis. Section 6 summarizes the contributions and guidelines for future research.

\section{Literature Review}

The transport of dangerous goods in an organizational and technical-technological sense represents a constant danger for all who come into direct or indirect contact with dangerous substances. Carriers who transport dangerous goods and perform the actions related to transport, as well as persons who directly handle or otherwise come into contact with dangerous goods, are obliged to comply with the regulations on the transport of dangerous goods. They are also obliged to take preventive and protective measures, which ensure the protection of human life and health, material goods, and the environment [10]. The rules also regulate actions related to transport, such as packaging of dangerous goods, loading, reloading, unloading, additional manipulations, procedures of transport staff in the event of a traffic accident, and incident [11]. Practically, regulations on the transport of dangerous goods regulate actions and activities in a broader context compared to the classical understanding of transport, which makes this form of transport much more complex, as confirmed by [12]. In order for the number of accidents with dangerous substances to be as small as possible, it is necessary to establish certain rules of conduct for all persons who come into contact with them or may influence them in any way [13]. That is why numerous international and national acts in the transport of dangerous goods have been defined and adopted. Taking into account the heterogeneous structure of regulations in this area, the 
most important legal acts at the international and national levels are presented in the following.

The more organized the activities of the economy, the richer the forms and contents of life and work, and the greater the differentiation and contradictions, the greater the need for a larger number of legal norms [14]. Harmonization and regulation of numerous, diverse, and complex relations in the transport of dangerous goods require the definition of various legal norms in terms of organization, responsibility, conduct, and other requirements in order for this area to function effectively. The number and content of legal norms follow the development of the area in which they are applied so that this justifies a larger number of legal acts in the field of transport of dangerous goods. The structure of legal acts regulating the transport of dangerous goods is very heterogeneous. Figure 1 highlights the most important legal acts at the international and national levels, which regulate this area.

In order to create conditions for safe processes for transporting dangerous goods, the rules governing these processes have been established. To this end, in 1954, the United Nations (UN) formed an expert team that gave recommendations for the creation of unique criteria related to marking, classification, vehicles, devices on vehicles, permits, and so on. Based on these recommendations, in 1957, the UN prepared agreements, which became binding on all signatories to the agreement. Generations of experts of various profiles, primarily chemists and engineers of all necessary professions, are constantly developing technical and technological systems for the safe transport of dangerous goods. Regulations on the transport of dangerous goods are individually regulated for each type of transport, and it is one of the most harmonized logistics areas at the international level. In particular, regulations for road, rail, air, river, and sea transport have been adopted (Figure 2) and have been largely harmonized.

Based on the uniform rules accepted by the countries' signatories to these agreements, the unhindered transport of dangerous goods through different countries is enabled, without any restrictions in terms of different standards in packaging, handling, and transport of dangerous goods.

Participants in the transport of dangerous goods, in terms of the type and extent of foreseeable hazards, shall take appropriate measures to prevent adverse events or reduce their effects if they occur. In any case, they must comply with the relevant requirements of international agreements and applicable laws and regulations.

The main participants in the transport of dangerous goods are as follows [15]:

(i) Consignor is a company, other legal entities, or entrepreneur, which ships dangerous goods on his behalf and for its own account or for a third party. If the transport is performed on the basis of a transport contract, the consignor is considered to be the consignor under this contract. The consignor of dangerous goods is obliged to hand over the consignment for transport in accordance with the provisions of ADR. (ii) Carrier is a company, other legal entities, or entrepreneur, which performs transport with or without a transport contract.

(iii) Consignee is a company, other legal entities, or an entrepreneur in accordance with a transport contract. If the consignee designates a third party in accordance with the provisions of the transport contract, then the third party shall be deemed to be the consignee. If the transport is performed without a transport contract, then the consignee is a company, other legal entities, or an entrepreneur that takes over dangerous goods after their arrival.

\section{Materials and Methods}

The overall methodology of this research can be presented through four phases given in Figure 3. Parts of the research are presented, starting from recognizing the needs for research and data collection in Phase I to sensitivity analysis and comparative analysis in Phase IV in order to verify the results.

Phase II presented in Figure 3 is the formation of the MCDM model, which includes nine criteria, 11 alternatives, and 5 decision-makers who participated in group decisionmaking. Phase III refers to enriching the scientific literature with the development of a novel Fuzzy-Rough MCDM model created by integrating the IMF SWARA and Rough MARCOS methods. The last phase is a sensitivity analysis through changes in the values of weight coefficients. Thirty scenarios were formed in which the values of the three most significant criteria were reduced by $5-95 \%$. Also, in this phase, the dynamic influence of the change in the size of the initial matrix was determined, which means deleting the lastranked alternative in the initial matrix. In addition, a comparative analysis was performed with five other Rough MCDM methods. The steps of the proposed methodology with the main operations of fuzzy and rough numbers are presented in detail in the following.

Today, the application of the rough set theory and its integration with some of MCDM methods are very popular and give good results because of treating uncertainties or vagueness. In this research, the Rough MARCOS method has been used for many reasons. MARCOS method is one of the recently developed methods that have many advantages: using compromise solution in order to get better final results, stability from the aspect of initial matrix size, consideration of a set of large parameters, robustness, and so on.

3.1. Preliminaries: Operations with Rough and Fuzzy Numbers. The operational laws of two rough numbers $\mathrm{RN}(\alpha)$ and $\mathrm{RN}(\beta)$ are as follows [16]:

Addition (+):

$$
\mathrm{RN}(\alpha)+\mathrm{RN}(\beta)=\left[\begin{array}{c}
\underline{\operatorname{Lim}}(\alpha)+\underline{\operatorname{Lim}}(\beta), \\
\overline{\operatorname{Lim}}(\alpha)+\overline{\operatorname{Lim}}(\beta)
\end{array}\right] .
$$

Subtraction (-): 
Regulations in the transport of dangerous goods

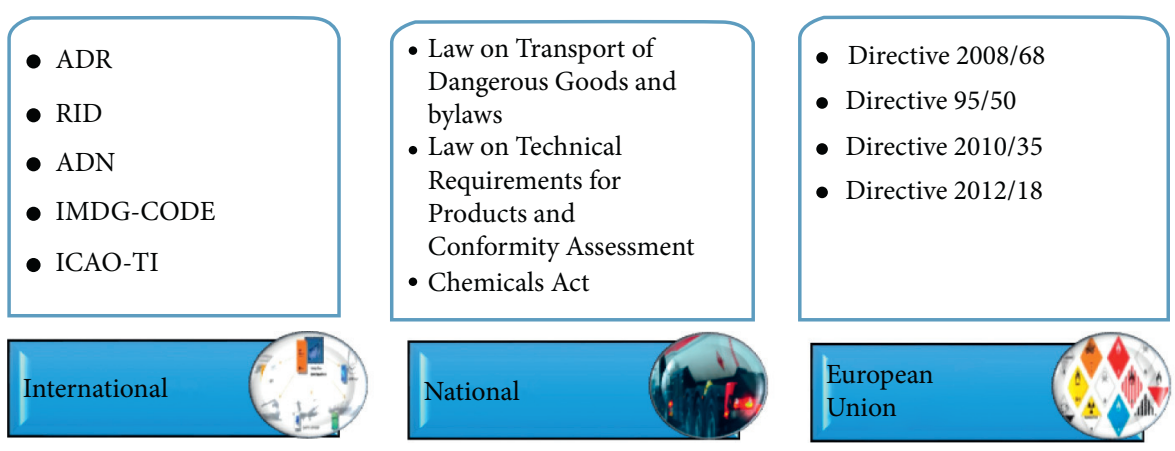

Figure 1: Legal acts on the transport of dangerous goods.
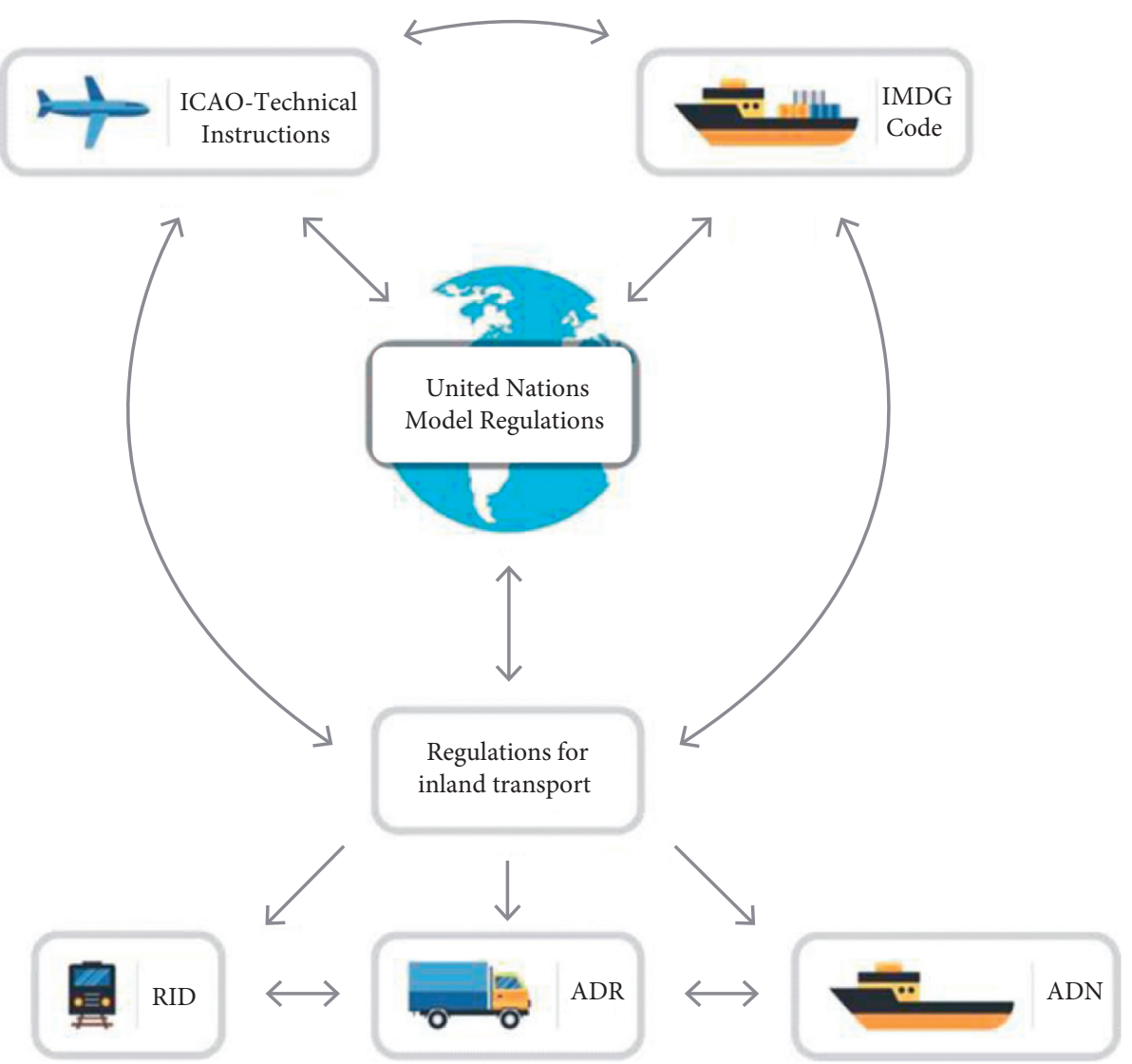

FigURE 2: International regulations on the transport of dangerous goods.

$$
\mathrm{RN}(\alpha)-\mathrm{RN}(\beta)=\left[\begin{array}{l}
\underline{\operatorname{Lim}}(\alpha)-\overline{\operatorname{Lim}}(\beta), \\
\overline{\operatorname{Lim}}(\alpha)-\underline{\operatorname{Lim}}(\beta)
\end{array}\right] .
$$

Multiplication $(\times)$ :

$$
\mathrm{RN}(\alpha) \times \mathrm{RN}(\beta)=\left[\begin{array}{l}
\underline{\operatorname{Lim}}(\alpha) \times \underline{\operatorname{Lim}}(\beta), \\
\overline{\operatorname{Lim}}(\alpha) \times \overline{\operatorname{Lim}}(\beta)
\end{array}\right] .
$$

Division (/):

$$
\frac{\mathrm{RN}(\alpha)}{\operatorname{RN}(\beta)}=\left[\begin{array}{l}
\underline{\operatorname{Lim}}(\alpha) / \overline{\operatorname{Lim}}(\beta), \\
\overline{\operatorname{Lim}}(\alpha) / \underline{\operatorname{Lim}}(\beta)
\end{array}\right]
$$

Scalar multiplication of rough number $\mathrm{RN}(\alpha)$ :

$$
\mu \times \mathrm{RN}(\alpha)=[\mu \times \underline{\operatorname{Lim}}(\alpha), \mu \times \overline{\operatorname{Lim}}(\alpha)],
$$

where $\mu$ is a nonzero constant.

The TFN can be denoted by $\bar{A}=(l, m, u)$. The operational laws of TFN $\bar{A}=\left(l_{1}, m_{1}, u_{1}\right)$ and $\bar{A}=\left(l_{2}, m_{2}, u_{2}\right)$ are as follows [17]:

Addition:

$$
\overline{A_{1}}+\overline{A_{2}}=\left(l_{1}, m_{1}, u_{1}\right)+\left(l_{2}, m_{2}, u_{2}\right)=\left(l_{1}+l_{2}, m_{1}+m_{2}, u_{1}+u_{2}\right) .
$$

Multiplication: 


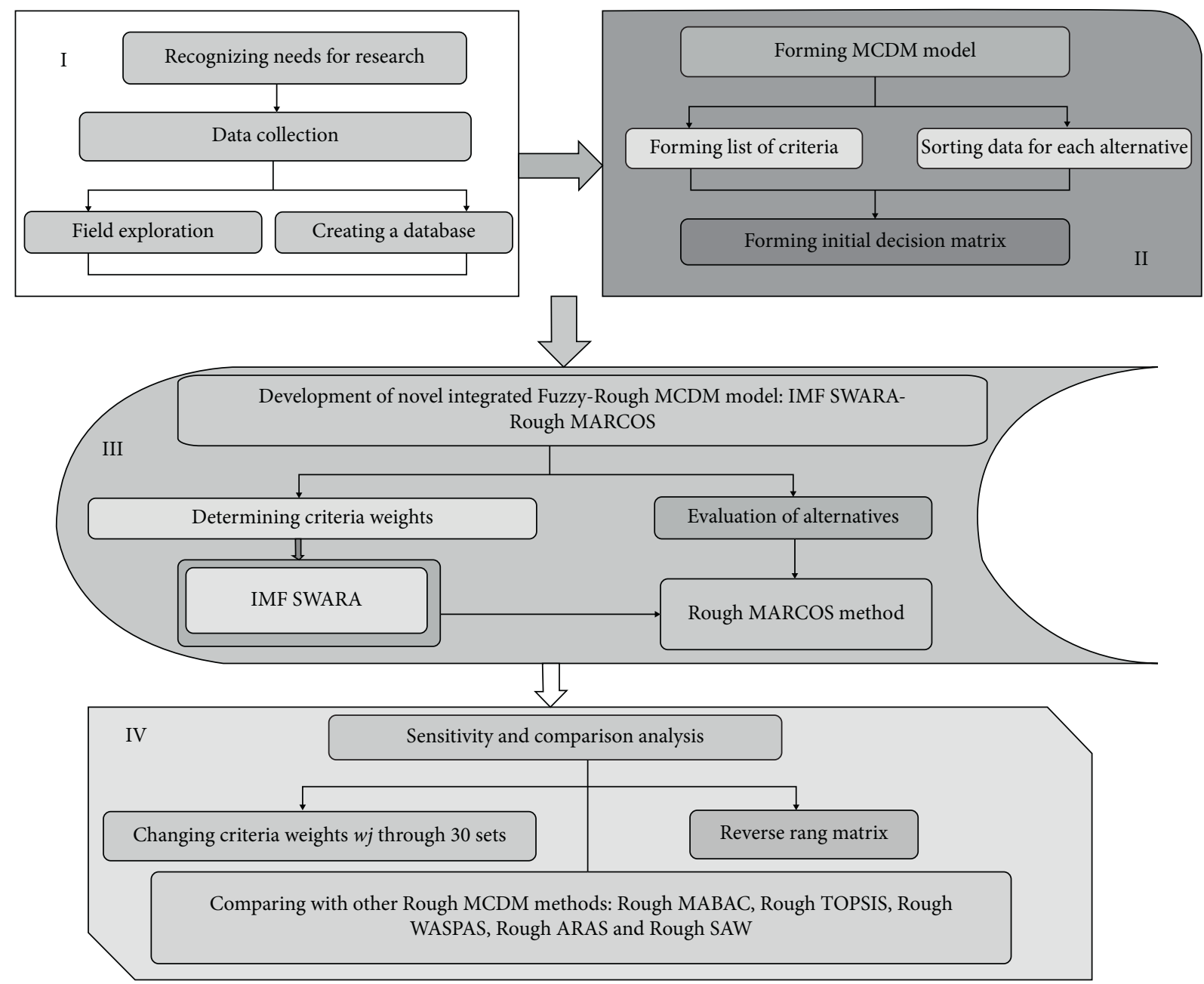

FIgURE 3: Methodology of the research.

$\overline{A_{1}} \times \overline{A_{2}}=\left(l_{1}, m_{1}, u_{1}\right) \times\left(l_{2}, m_{2}, u_{2}\right)=\left(l_{1} \times l_{2}, m_{1} \times m_{2}, u_{1} \times u_{2}\right)$.

Subtraction:

$\overline{A_{1}}-\overline{A_{2}}=\left(l_{1}, m_{1}, u_{1}\right)-\left(l_{2}, m_{2}, u_{2}\right)=\left(l_{1}-u_{2}, m_{1}-m_{2}, u_{1}-l_{2}\right)$.

Division:

$$
\frac{\overline{A_{1}}}{\overline{\overline{A_{2}}}}=\frac{\left(l_{1}, m_{1}, u_{1}\right)}{\left(l_{2}, m_{2}, u_{2}\right)}=\left(\frac{l_{1}}{u_{2}}, \frac{m_{1}}{m_{2}}, \frac{u_{1}}{l_{2}}\right) .
$$

Reciprocal:

$$
{\overline{A_{1}}}^{-1}=\left(l_{1}, m_{1}, u_{1}\right)^{-1}=\left(\frac{1}{u_{1}}, \frac{1}{m_{1}}, \frac{1}{l_{1}}\right) .
$$

3.2. Bonferroni Aggregator. The Bonferroni aggregator was used $[18,19]$ :

$$
a_{j}=\left(\frac{1}{e(e-1)} \sum_{\substack{i, j=1 \\ i \neq j}}^{e} a_{i}^{p} \otimes a_{j}^{q}\right)^{1 / p+q} .
$$

In this research, $e$ represents the number of decisionmakers, while $p, q \geq 0$ are a set of nonnegative numbers.

3.3. IMF SWARA Method. The improved fuzzy SWARA method has been developed by Vrtagić et al. [20] and consists of the following steps.

Step 1. After defining all the criteria on the basis of which the decision was made, it is necessary to arrange them in descending order based on their expected significance.

Step 2. Starting from the previously determined rank, the relatively smaller significance of the criterion (criterion $\mathrm{Cj}$ ) 
was determined in relation to the previous one $(\mathrm{Cj}-1)$, and that was repeated for each subsequent criterion. This relation, that is, the comparative significance of the average value, is denoted by $\overline{s_{j}}$. An adequate TFN scale that enables the precise and good quality determination of the significance of criteria using IMF SWARA is shown in Table 1.

Step 3. Determine the fuzzy coefficient (12):

$$
\overline{k_{j}}=\left\{\begin{array}{l}
\overline{1} \quad j=1 \\
\overline{s_{j}} \oplus \overline{1} \quad j>1
\end{array}\right.
$$
by $\overline{s_{j}}$.

Comparative significance of the average value is denoted

Step 4. Determine the calculated weights $\overline{q_{j}}(13)$ :

$$
\overline{q_{j}}= \begin{cases}\overline{1} & j=1 \\ \frac{\overline{q_{j-1}}}{\overline{k_{j}}} & j>1\end{cases}
$$

$\overline{k_{j}}$ is the fuzzy coefficient from the previous step.

Step 5. Calculate the fuzzy weight coefficients as follows:

$$
\overline{w_{j}}=\frac{\overline{q_{j}}}{\sum_{j=1}^{m} \overline{q_{j}}},
$$

where $w_{j}$ represents the fuzzy relative weight of the criteria $j$ and $m$ represents the total number of criteria.

3.4. Rough MARCOS. The Rough MARCOS (R-MARCOS) method [21] is used to evaluate transportation companies in the field of dangerous goods. The steps of R-MARCOS are as follows:

Step 6. The Rough Decision Matrix $(\mathrm{RN}(V))$ is organized as follows:

$$
\mathrm{RN}(V)=\left[v_{\mathrm{ij}}^{L}, v_{\mathrm{ij}}^{U}\right]_{m \times n},
$$

where $v_{\mathrm{ij}}$ denotes values of the initial rough matrix consisting of $m$ alternatives and $n$ criteria.

Step 7. The Extended Rough Matrix RN(EV) is arranged by adding anti-ideal RN(AID) and ideal RN(ID) solutions to the matrix.

$$
\begin{gathered}
\mathrm{RN}(\mathrm{AID})=\left[v_{\mathrm{aid}}^{L}, v_{\mathrm{aid}}^{U}\right]= \begin{cases}\min _{i}\left[v_{\mathrm{ij}}^{L}, v_{\mathrm{ij}}^{U}\right] \text { if } & j \in B \\
\max _{i}\left[v_{\mathrm{ij}}^{L}, v_{\mathrm{ij}}^{U}\right] \text { if } & j \in C\end{cases} \\
\mathrm{RN}(\mathrm{ID})=\left[v_{\mathrm{id}}^{L}, v_{\mathrm{id}}^{U}\right]= \begin{cases}\max _{i}\left[v_{\mathrm{ij}}^{L}, v_{\mathrm{ij}}^{U}\right] \text { if } & j \in B \\
\min _{i}\left[v_{\mathrm{ij}}^{L}, v_{\mathrm{ij}}^{U}\right] \text { if } & j \in C\end{cases}
\end{gathered}
$$

AID is anti-ideal, while ID is the ideal solution. In equations (16) and (17), $B$ and $C$ indicate the beneficial and cost criteria, respectively.

Step 8. The Rough Normalized Matrix RN $(T)$ is obtained by equations (19) and (20).

$$
\begin{aligned}
& \operatorname{RN}(T)=\left[t_{\mathrm{ij}}^{L}, t_{\mathrm{ij}}^{U}\right]_{m \times n} \cdot \\
& {\left[t_{\mathrm{ij}}^{L}, t_{\mathrm{ij}}^{U}\right]=\left[\frac{v_{\mathrm{ij}}^{L}}{v_{\mathrm{id}}^{U}}, \frac{v_{\mathrm{ij}}^{U}}{v_{\mathrm{id}}^{L}}\right] \text { if } \quad j \in B .} \\
& {\left[t_{\mathrm{ij}}^{L}, t_{\mathrm{ij}}^{U}\right]=\left[\frac{v_{\mathrm{id}}^{L}}{v_{\mathrm{ij}}^{U}}, \frac{v_{\mathrm{id}}^{U}}{v_{\mathrm{ij}}^{L}}\right] \text { if } \quad j \in C,}
\end{aligned}
$$

where $v_{\mathrm{ij}}^{L}$ and $v_{\mathrm{ij}}^{U}$ are low and upper values from the initial decision matrix, respectively. Elements $v_{\mathrm{id}}^{L}$ and $v_{\mathrm{id}}^{U}$ represent the low and upper of the ideal solution.

Step 9. Rough weighted normalized matrix $\mathrm{RN}(E)$ is computed by

$$
\mathrm{RN}(E)=\left[e_{\mathrm{ij}}^{L}, e_{\mathrm{ij}}^{U}\right]=\left[t_{\mathrm{ij}}^{L} \times w_{j}^{L}, t_{\mathrm{ij}}^{U} \times w_{j}^{U}\right] .
$$

In this step, it is needed to multiply values of criteria weights with values from the normalized matrix.

Step 10. $\mathrm{RN}(Z)$ is computed by

$$
\mathrm{RN}(Z)=\left[z_{i}^{L}, z_{i}^{U}\right]=\sum_{j=1}^{n}\left[e_{\mathrm{ij}}^{L}, e_{\mathrm{ij}}^{U}\right],
$$

where $\mathrm{RN}(Z)$ represents the sum of the elements of matrix E.

Step 11. Rough utility degrees of alternatives $\mathrm{RN}\left(Y_{i}^{-}\right)$and $\mathrm{RN}\left(Y_{i}^{+}\right)$are calculated as follows:

$$
\begin{aligned}
& \mathrm{RN}\left(Y_{i}^{-}\right)=\left[y_{i}^{-L}, y_{i}^{-U}\right]=\left[\frac{z_{i}^{L}}{z_{\text {aid }}^{U}}, \frac{z_{i}^{U}}{z_{\text {aid }}^{L}}\right], \\
& \operatorname{RN}\left(Y_{i}^{+}\right)=\left[y_{i}^{+L}, y_{i}^{+U}\right]=\left[\frac{z_{i}^{L}}{z_{\text {id }}^{U}}, \frac{z_{i}^{U}}{z_{\text {id }}^{L}}\right] .
\end{aligned}
$$

where $z_{i}^{L}$ and $z_{i}^{U}$ are the low and upper values from the previous summed matrix, respectively. Elements $z_{\text {id }}^{L}$ and $z_{\text {id }}^{U}$ represent the low and upper with respect to ideal solution.

Step 12. Rough utility degrees $\left(\mathrm{RN}\left(Y_{i}^{-}\right)\right.$and $\left.\mathrm{RN}\left(Y_{i}^{+}\right)\right)$are converted into crisp $Y_{i}^{-}$and $Y_{i}^{+}$using equations (25) and (26):

$$
\begin{aligned}
& Y_{i}^{-}=\frac{y_{i}^{-L}+y_{i}^{-U}}{2} . \\
& Y_{i}^{+}=\frac{y_{i}^{+L}+y_{i}^{+U}}{2} .
\end{aligned}
$$


Step 13. The utility functions in relation to the anti-ideal $f\left(Y_{i}^{-}\right)$and ideal $f\left(Y_{i}^{+}\right)$solutions are computed by equations (27) and (28), respectively:

$$
f\left(Y_{i}\right)=\frac{Y_{i}^{+}+Y_{i}^{-}}{1+1-f\left(Y_{i}^{+}\right) / f\left(Y_{i}^{+}\right)+1-f\left(Y_{i}^{-}\right) / f\left(Y_{i}^{-}\right)},
$$

where

$$
\begin{aligned}
& f\left(Y_{i}^{-}\right)=\frac{Y_{i}^{+}}{Y_{i}^{+}+Y_{i}^{-}} . \\
& f\left(Y_{i}^{+}\right)=\frac{Y_{i}^{-}}{Y_{i}^{+}+Y_{i}^{-}} .
\end{aligned}
$$

Step 14. The alternatives are sorted from the highest utility function to the lowest utility function.

\section{Case Study}

In this research, 11 companies have been evaluated for transporting dangerous goods in the territory of the Republic of Serbia on the basis of nine criteria formed on the basis of a review of the literature and discussion with experts in this field. It is important to note that this is group decision-making in which five experts took part, defining the significance of the criteria and evaluating the transport companies on the basis of the criteria. A set of nine criteria with labels and definitions is given in Table 2.

Criteria for evaluating the work of companies for the transport of dangerous goods are defined in two phases. The first phase involved the identification of criteria based on the requirements of the regulations in the transport of dangerous goods defined in the Agreement Concerning the International Carriage of Dangerous Goods by Road (ADR) [22]. The second phase included the expert opinion based on experience in practical work as an advisor in companies for the transport of dangerous goods. The synthesis of the results of these two phases identified key criteria for evaluating the work of companies for the transport of dangerous goods.

\section{Results and Discussion}

5.1. Determination of Weight Coefficients Using the IMF SWARA Method. In order to adequately rank alternatives, it is necessary to calculate the weights of the criteria. In this case, it is done using the IMF SWARA method, and the overall calculation with the final weights is shown in Table 3.

The calculation is performed as follows. First, on the basis of the previously defined scale shown in Table 1, a matrix $\overline{s_{j}}$ is obtained which represents the relation of the criteria in terms of significance. After that, a matrix $\overline{k_{j}}$ is calculated as follows:

$$
\begin{aligned}
& \overline{k_{1}}=[1.000,1.000,1000], \\
& \overline{k_{2}}=[1.222,1.250,1.286]=[1+2 / 9,1+1 / 4,1+2 / 7] .
\end{aligned}
$$

The elements of matrix $\overline{q_{j}}$ are obtained as follows:

$$
\overline{q_{2}}=\frac{\overline{q_{2-1}}}{\overline{k_{2}}}=\frac{1.000}{1.286}, \frac{1.000}{1.250}, \frac{1.000}{1.222}=[0.778,0.800,0.818] \text {. }
$$

Further, fuzzy weights $\overline{w_{j}}$ are calculated as follows:

$$
\overline{w_{1}}=\frac{\overline{q_{1}}}{\sum_{j=1}^{9} \overline{q_{j}}}=\frac{1.000}{4.777}, \frac{1.000}{4.485}, \frac{1.000}{4.154}=[0.209,0.223,0.241] \text {. }
$$

After that, the defuzzified values shown in the last column in Table 3 are calculated. The calculation for the second, third, fourth, and fifth experts are performed in the same way and shown in Tables $4-7$, respectively.

After calculating the values of the weight criteria for each expert separately, it is necessary to perform their averaging so that they can be further included in the Rough MARCOS model. For these purposes, equation (11), that is, Bonferroni aggregator, is applied in the following way for the first criterion:

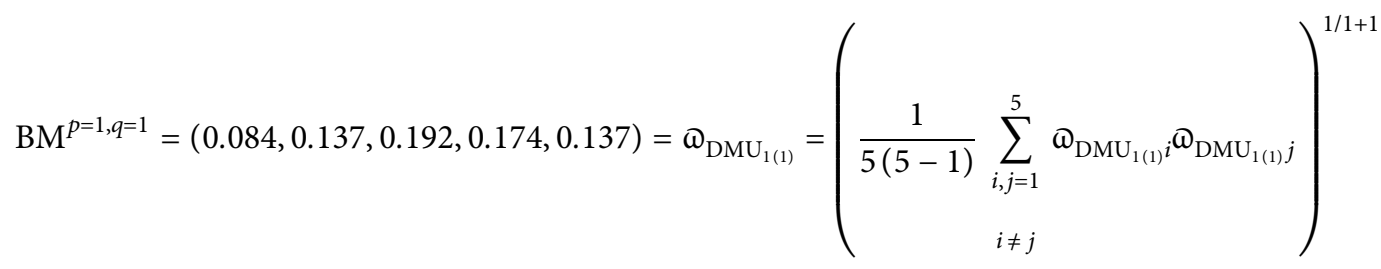

$$
\begin{aligned}
& \left.=\left(0.050\left(\begin{array}{c}
0.084^{1} \cdot 0.137^{1}+0.184^{1} \cdot 0.192^{1}+0.084^{1} \cdot 0.174^{1}+0.084^{1} \cdot 0.137^{1}+ \\
0.137^{1} \cdot 0.084^{1}+0.137^{1} \cdot 0.192^{1}+0.137^{1} \cdot 0.174^{1}+0.137^{1} \cdot 0.137^{1}+\ldots \\
+0.137^{1} \cdot 0.084^{1}+0.137^{1} \cdot 0.192^{1}+0.137^{1} \cdot 0.174^{1}+0.137^{1} \cdot 0.137^{1}
\end{array}\right)\right)\right)^{1 / 1+1}=0.143 .
\end{aligned}
$$


TABLE 1: Linguistics and the TFN scale for the evaluation of the criteria in the improved IMF SWARA method.

\begin{tabular}{|c|c|c|c|c|}
\hline Linguistic variable & Abbreviation & & TFN scal & \\
\hline Absolutely less significant & ALS & 1.000 & 1.000 & 1.000 \\
\hline Dominantly less significant & DLS & $1 / 2$ & $2 / 3$ & 1.000 \\
\hline Much less significant & MLS & $2 / 5$ & $1 / 2$ & $2 / 3$ \\
\hline Really less significant & RLS & $1 / 3$ & $2 / 5$ & $1 / 2$ \\
\hline Less significant & LS & $2 / 7$ & $1 / 3$ & $2 / 5$ \\
\hline Moderately less significant & MDLS & $1 / 4$ & $2 / 7$ & $1 / 3$ \\
\hline Weakly less significant & WLS & $2 / 9$ & $1 / 4$ & $2 / 7$ \\
\hline Equally significant & ES & 0.000 & 0.000 & 0.000 \\
\hline
\end{tabular}

TABLE 2: List and definition of criteria applied in this study.

\begin{tabular}{|c|c|c|}
\hline Mark & Criteria & Description of criteria \\
\hline $\mathrm{C} 1$ & $\begin{array}{l}\text { Dangerous goods classified and permitted } \\
\text { under ADR }\end{array}$ & $\begin{array}{l}\text { The carrier makes sure that the dangerous goods are classified and permitted for } \\
\text { transport in accordance with ADR or relies on data made available by other participants } \\
\text { in the transport of dangerous goods in accordance with 1.4.2.2.2 ADR }\end{array}$ \\
\hline $\mathrm{C} 2$ & $\begin{array}{l}\text { The consignor made all the necessary } \\
\text { information available }\end{array}$ & $\begin{array}{l}\text { The carrier makes sure that the consignor has made all the information required by } \\
\text { ADR related to transported goods before transport available or relies on the } \\
\text { information made available by other participants in the transport of dangerous goods in } \\
\text { accordance with 1.4.2.2.2 ADR }\end{array}$ \\
\hline $\mathrm{C} 3$ & Documents in the transport unit & $\begin{array}{l}\text { (i) Prescribed documents are in the transport unit } \\
\text { (ii) Transport documents completed in accordance with ADR requirements } \\
\text { (iii) Written instructions } \\
\text { (iv) Means of identification with a photograph for each member of a vehicle crew } \\
\text { (v) ADR vehicle approval certificate (for vehicles declared as EX/II, EX/III, FL, AT, or } \\
\text { MEMU) } \\
\text { (vi) Certificate of professional competence for the driver of a vehicle for transporting } \\
\text { dangerous goods } \\
\text { (vii) A copy of competent authority's approval for transporting dangerous goods of } \\
\text { class } 1 \text {, class } 7 \text {, or hazardous waste }\end{array}$ \\
\hline $\mathrm{C} 4$ & Visual inspection of the transport unit & $\begin{array}{l}\text { The carrier makes sure by visual checks that the vehicle or goods do not have obvious } \\
\text { defects, leaks, or cracks, that parts of the equipment are not missing, and that there are } \\
\text { no remains of dangerous material with which it is filled on the outer walls of the tank, } \\
\text { and so on }\end{array}$ \\
\hline C5 & The testing time of tanks is controlled & $\begin{array}{l}\text { The carrier makes sure that, in the case of tank vehicles, battery vehicles, demountable } \\
\text { tanks, portable tanks, container tanks, and MEGC, the deadline for the next test has not } \\
\text { been exceeded }\end{array}$ \\
\hline C6 & Vehicle load is controlled & $\begin{array}{c}\text { The carrier checks that the vehicles are not overloaded (degree of tank filling, axle load } \\
\text { of the vehicle, etc.) }\end{array}$ \\
\hline $\mathrm{C} 7$ & Marking and labeling the transport unit & $\begin{array}{c}\text { The carrier makes sure that large hazard sheets, markings, and orange signs prescribed } \\
\text { in chapter } 5.3 \text { of the ADR are affixed to the transport unit }\end{array}$ \\
\hline $\mathrm{C} 8$ & Equipment in the transport unit & $\begin{array}{l}\text { The carrier makes sure that the transport unit contains the equipment prescribed in the } \\
\text { written instructions of the ADR for the transport unit, vehicle crew, and certain classes }\end{array}$ \\
\hline C9 & Documentation retention & $\begin{array}{l}\text { The carrier must keep a copy of the transport document for dangerous goods, } \\
\text { additional information, and documentation required in the ADR for a minimum } \\
\text { period of three months }\end{array}$ \\
\hline
\end{tabular}

TABLE 3: Calculation and values of weight coefficients obtained by the IMF SWARA method for the first expert E1.

\begin{tabular}{|c|c|c|c|c|c|c|c|c|c|c|c|c|c|}
\hline \multirow{2}{*}{$\frac{\mathrm{E} 1}{\mathrm{C} 8}$} & \multicolumn{3}{|c|}{$\overline{s_{j}}$} & \multicolumn{3}{|c|}{$\overline{k_{j}}$} & \multicolumn{3}{|c|}{$\overline{q_{j}}$} & \multicolumn{3}{|c|}{$\overline{w_{j}}$} & \multirow{2}{*}{$\begin{array}{c}\text { Crisp value } \\
0.224\end{array}$} \\
\hline & & & & 1.000 & 1.000 & 1.000 & 1.000 & 1.000 & 1.000 & 0.209 & 0.223 & 0.241 & \\
\hline $\mathrm{C} 3$ & $2 / 9$ & $1 / 4$ & $2 / 7$ & 1.222 & 1.250 & 1.286 & 0.778 & 0.800 & 0.818 & 0.163 & 0.178 & 0.197 & 0.179 \\
\hline $\mathrm{C} 7$ & $2 / 9$ & $1 / 4$ & $2 / 7$ & 1.222 & 1.250 & 1.286 & 0.605 & 0.640 & 0.669 & 0.127 & 0.143 & 0.161 & 0.143 \\
\hline C6 & $2 / 7$ & $1 / 3$ & $2 / 5$ & 1.286 & 1.333 & 1.400 & 0.432 & 0.480 & 0.521 & 0.090 & 0.107 & 0.125 & 0.107 \\
\hline $\mathrm{C} 2$ & 0.000 & 0.000 & 0.000 & 1.000 & 1.000 & 1.000 & 0.432 & 0.480 & 0.521 & 0.090 & 0.107 & 0.125 & 0.107 \\
\hline $\mathrm{C} 1$ & $1 / 4$ & $2 / 7$ & $1 / 3$ & 1.250 & 1.286 & 1.333 & 0.324 & 0.373 & 0.417 & 0.068 & 0.083 & 0.100 & 0.084 \\
\hline C5 & $2 / 9$ & $1 / 4$ & $2 / 7$ & 1.222 & 1.250 & 1.286 & 0.252 & 0.299 & 0.341 & 0.053 & 0.067 & 0.082 & 0.067 \\
\hline $\mathrm{C} 4$ & $1 / 4$ & $2 / 7$ & $1 / 3$ & 1.250 & 1.286 & 1.333 & 0.189 & 0.232 & 0.273 & 0.040 & 0.052 & 0.066 & 0.052 \\
\hline C9 & $1 / 4$ & $2 / 7$ & $1 / 3$ & 1.250 & 1.286 & 1.333 & 0.142 & 0.181 & 0.218 & 0.030 & 0.040 & 0.053 & 0.041 \\
\hline & & & & & & SUM & 4.154 & 4.485 & 4.777 & & & & \\
\hline
\end{tabular}


TABLE 4: Calculation and values of weight coefficients obtained by the IMF SWARA method for E2.

\begin{tabular}{|c|c|c|c|c|c|c|c|c|c|c|c|c|c|}
\hline E2 & & $\overline{s_{j}}$ & & & $\overline{k_{j}}$ & & & $\overline{q_{j}}$ & & & $\overline{w_{j}}$ & & Crisp value \\
\hline $\mathrm{C} 1$ & & & & 1.000 & 1.000 & 1.000 & 1.000 & 1.000 & 1.000 & 0.134 & 0.137 & 0.140 & 0.137 \\
\hline $\mathrm{C} 3$ & 0.000 & 0.000 & 0.000 & 1.000 & 1.000 & 1.000 & 1.000 & 1.000 & 1.000 & 0.134 & 0.137 & 0.140 & 0.137 \\
\hline C5 & 0.000 & 0.000 & 0.000 & 1.000 & 1.000 & 1.000 & 1.000 & 1.000 & 1.000 & 0.134 & 0.137 & 0.140 & 0.137 \\
\hline $\mathrm{C} 7$ & 0.000 & 0.000 & 0.000 & 1.000 & 1.000 & 1.000 & 1.000 & 1.000 & 1.000 & 0.134 & 0.137 & 0.140 & 0.137 \\
\hline $\mathrm{C} 8$ & 0.000 & 0.000 & 0.000 & 1.000 & 1.000 & 1.000 & 1.000 & 1.000 & 1.000 & 0.134 & 0.137 & 0.140 & 0.137 \\
\hline C9 & $2 / 9$ & $1 / 4$ & $2 / 7$ & 1.222 & 1.250 & 1.286 & 0.778 & 0.800 & 0.818 & 0.105 & 0.109 & 0.114 & 0.109 \\
\hline $\mathrm{C} 2$ & $2 / 9$ & $1 / 4$ & $2 / 7$ & 1.222 & 1.250 & 1.286 & 0.605 & 0.640 & 0.669 & 0.081 & 0.088 & 0.093 & 0.087 \\
\hline $\mathrm{C} 4$ & $1 / 4$ & $2 / 7$ & $1 / 3$ & 1.250 & 1.286 & 1.333 & 0.454 & 0.498 & 0.536 & 0.061 & 0.068 & 0.075 & 0.068 \\
\hline C6 & $2 / 7$ & $1 / 3$ & $2 / 5$ & 1.286 & 1.333 & 1.400 & 0.324 & 0.373 & 0.417 & 0.044 & 0.051 & 0.058 & 0.051 \\
\hline & & & & & & SUM & 7.160 & 7.311 & 7.440 & & & & \\
\hline
\end{tabular}

The final values of all weight coefficients are obtained in the same way by averaging the Bonferroni aggregator, and they are as follows:

$$
\begin{aligned}
w_{1}=0.143, w_{2} & =0.129, w_{3}=0.138, w_{4}=0.084, w_{5}=0.108 \\
w_{6} & =0.064, w_{7}=0.122, w_{8}=0.131, w_{9}=0.066
\end{aligned}
$$

The results obtained show that the most significant criteria are as follows: dangerous goods classified and permitted under ADR (C1) with a value of 0.143 , prescribed documents in the transport unit (C3) with a value of 0.138 , and the equipment in the transport unit (C8) with a value of 0.131 , while C6, vehicle load control, is ranked the worst with a value of 0.064 .

5.2. Ranking of Companies for Transporting Dangerous Goods Using the Rough MARCOS Method. In order to perform the calculation using the Rough MARCOS method, it is first necessary to determine the group rough matrix by transforming individual estimates shown in Table 8. Experts for evaluating the work of transport companies of dangerous goods were selected based on the following criteria:

(i) Property of a certificate of safety advisor in the transport of dangerous goods

(ii) Work experience in companies for transport of dangerous goods for at least 10 years

(iii) Membership in professional organizations and committees for the transport of dangerous goods

(iv) Participation in the writing of national regulations (laws and bylaws) in the transport of dangerous goods

(v) Participation in the preparation of expert studies related to the analysis of the transport of dangerous goods

An example of calculating the values of the first alternative according to the sixth criterion for the initial rough matrix shown in Table 9 is given as follows:

$$
\begin{aligned}
\bar{A}_{11} & =\{5,9,7,7,9\}, \\
\underline{\operatorname{Lim}}(5) & =5, \overline{\operatorname{Lim}}(5)=\frac{1}{5}(5+9+7+7+9)=7.4, \\
\underline{\operatorname{Lim}}(9) & =\frac{1}{5}(5+9+7+7+9)=7.4, \overline{\operatorname{Lim}}(9)=9, \\
\underline{\operatorname{Lim}}(7) & =\frac{1}{3}(5+7+7)=6.33, \overline{\operatorname{Lim}}(7)=\frac{1}{4}(9+7+7+9)=8, \\
\operatorname{RN}\left(A_{1}^{1}\right) & =[5,7.4] ; \mathrm{RN}\left(A_{1}^{2}\right)=\mathrm{RN}\left(A_{1}^{5}\right)=[7.4,9] ; \mathrm{RN}\left(A_{3}^{3}\right)=\mathrm{RN}\left(A_{1}^{4}\right)=[6.33,8] ;, \\
A_{11}^{L} & =\frac{A_{11}^{1}+A_{11}^{2}+A_{11}^{3}+A_{11}^{4}+A_{11}^{5}}{S}=\frac{5+7.4+6.33+6.33+7.4}{5}=6.49, \\
A_{11}^{U} & =\frac{A_{11}^{1}+A_{11}^{2}+A_{11}^{3}+A_{11}^{4}+A_{11}^{5}}{S}=\frac{7.4+9+8+8+9}{5}=8.28 .
\end{aligned}
$$


TABLE 5: Calculation and values of weight coefficients obtained by the IMF SWARA method for E3.

\begin{tabular}{|c|c|c|c|c|c|c|c|c|c|c|c|c|c|}
\hline \multirow{2}{*}{$\frac{\mathrm{E} 3}{\mathrm{C} 2}$} & \multicolumn{3}{|c|}{$\overline{s_{j}}$} & \multicolumn{3}{|c|}{$\overline{k_{j}}$} & \multicolumn{3}{|c|}{$\overline{q_{j}}$} & \multicolumn{3}{|c|}{$\overline{w_{j}}$} & \multirow{2}{*}{$\begin{array}{c}\text { Crisp value } \\
0.240\end{array}$} \\
\hline & & & & 1.000 & 1.000 & 1.000 & 1.000 & 1.000 & 1.000 & 0.224 & 0.239 & 0.259 & \\
\hline $\mathrm{C} 1$ & $2 / 9$ & $1 / 4$ & $2 / 7$ & 1.222 & 1.250 & 1.286 & 0.778 & 0.800 & 0.818 & 0.174 & 0.192 & 0.212 & 0.192 \\
\hline $\mathrm{C} 4$ & $2 / 9$ & $1 / 4$ & $2 / 7$ & 1.222 & 1.250 & 1.286 & 0.605 & 0.640 & 0.669 & 0.136 & 0.153 & 0.173 & 0.154 \\
\hline C8 & $2 / 7$ & $1 / 3$ & $2 / 5$ & 1.286 & 1.333 & 1.400 & 0.432 & 0.480 & 0.521 & 0.097 & 0.115 & 0.135 & 0.115 \\
\hline C5 & $2 / 9$ & $1 / 4$ & $2 / 7$ & 1.222 & 1.250 & 1.286 & 0.336 & 0.384 & 0.426 & 0.075 & 0.092 & 0.110 & 0.092 \\
\hline $\mathrm{C} 3$ & $1 / 4$ & $2 / 7$ & $1 / 3$ & 1.250 & 1.286 & 1.333 & 0.252 & 0.299 & 0.341 & 0.057 & 0.072 & 0.088 & 0.072 \\
\hline C7 & $2 / 9$ & $1 / 4$ & $2 / 7$ & 1.222 & 1.250 & 1.286 & 0.196 & 0.239 & 0.279 & 0.044 & 0.057 & 0.072 & 0.058 \\
\hline C6 & $1 / 4$ & $2 / 7$ & $1 / 3$ & 1.250 & 1.286 & 1.333 & 0.147 & 0.186 & 0.223 & 0.033 & 0.045 & 0.058 & 0.045 \\
\hline C9 & $2 / 9$ & $1 / 4$ & $2 / 7$ & 1.222 & 1.250 & 1.286 & 0.114 & 0.149 & 0.183 & 0.026 & 0.036 & 0.047 & 0.036 \\
\hline & & & & & & SUM & 3.860 & 4.176 & 4.459 & & & & \\
\hline
\end{tabular}

TABLE 6: Calculation and values of weight coefficients obtained by the IMF SWARA method for E4.

\begin{tabular}{|c|c|c|c|c|c|c|c|c|c|c|c|c|c|}
\hline E4 & \multicolumn{3}{|c|}{$\overline{s_{j}}$} & \multicolumn{3}{|c|}{$\overline{k_{j}}$} & \multicolumn{3}{|c|}{$\overline{q_{j}}$} & \multicolumn{3}{|c|}{$\overline{w_{j}}$} & \multirow{2}{*}{$\begin{array}{c}\text { Crisp value } \\
0.174\end{array}$} \\
\hline $\mathrm{C} 1$ & & & & 1.000 & 1.000 & 1.000 & 1.000 & 1.000 & 1.000 & 0.168 & 0.174 & 0.182 & \\
\hline $\mathrm{C} 3$ & 0.000 & 0.000 & 0.000 & 1.000 & 1.000 & 1.000 & 1.000 & 1.000 & 1.000 & 0.168 & 0.174 & 0.182 & 0.174 \\
\hline $\mathrm{C} 2$ & $2 / 9$ & $1 / 4$ & $2 / 7$ & 1.222 & 1.250 & 1.286 & 0.778 & 0.800 & 0.818 & 0.130 & 0.139 & 0.149 & 0.139 \\
\hline C7 & 0.000 & 0.000 & 0.000 & 1.000 & 1.000 & 1.000 & 0.778 & 0.800 & 0.818 & 0.130 & 0.139 & 0.149 & 0.139 \\
\hline C5 & $2 / 9$ & $1 / 4$ & $2 / 7$ & 1.222 & 1.250 & 1.286 & 0.605 & 0.640 & 0.669 & 0.101 & 0.111 & 0.122 & 0.111 \\
\hline $\mathrm{C} 4$ & $2 / 9$ & $1 / 4$ & $2 / 7$ & 1.222 & 1.250 & 1.286 & 0.471 & 0.512 & 0.548 & 0.079 & 0.089 & 0.100 & 0.089 \\
\hline C6 & $2 / 9$ & $1 / 4$ & $2 / 7$ & 1.222 & 1.250 & 1.286 & 0.366 & 0.410 & 0.448 & 0.061 & 0.071 & 0.081 & 0.071 \\
\hline $\mathrm{C} 8$ & $2 / 9$ & $1 / 4$ & $2 / 7$ & 1.222 & 1.250 & 1.286 & 0.285 & 0.328 & 0.367 & 0.048 & 0.057 & 0.067 & 0.057 \\
\hline C9 & $2 / 9$ & $1 / 4$ & $2 / 7$ & 1.222 & 1.250 & 1.286 & 0.221 & 0.262 & 0.300 & 0.037 & 0.046 & 0.055 & 0.046 \\
\hline & & & & & & SUM & 5.503 & 5.751 & 5.968 & & & & \\
\hline
\end{tabular}

TABLE 7: Calculation and values of weight coefficients obtained by the IMF SWARA method for E5.

\begin{tabular}{|c|c|c|c|c|c|c|c|c|c|c|c|c|c|}
\hline E5 & & $\overline{s_{j}}$ & & & $\overline{k_{j}}$ & & & $\overline{q_{j}}$ & & & $\overline{w_{j}}$ & & Crisp value \\
\hline $\mathrm{C} 1$ & & & & 1.000 & 1.000 & 1.000 & 1.000 & 1.000 & 1.000 & 0.134 & 0.137 & 0.140 & 0.137 \\
\hline $\mathrm{C} 3$ & 0.000 & 0.000 & 0.000 & 1.000 & 1.000 & 1.000 & 1.000 & 1.000 & 1.000 & 0.134 & 0.137 & 0.140 & 0.137 \\
\hline C5 & 0.000 & 0.000 & 0.000 & 1.000 & 1.000 & 1.000 & 1.000 & 1.000 & 1.000 & 0.134 & 0.137 & 0.140 & 0.137 \\
\hline C7 & 0.000 & 0.000 & 0.000 & 1.000 & 1.000 & 1.000 & 1.000 & 1.000 & 1.000 & 0.134 & 0.137 & 0.140 & 0.137 \\
\hline $\mathrm{C} 8$ & 0.000 & 0.000 & 0.000 & 1.000 & 1.000 & 1.000 & 1.000 & 1.000 & 1.000 & 0.134 & 0.137 & 0.140 & 0.137 \\
\hline $\mathrm{C} 9$ & $2 / 9$ & $1 / 4$ & $2 / 7$ & 1.222 & 1.250 & 1.286 & 0.778 & 0.800 & 0.818 & 0.105 & 0.109 & 0.114 & 0.109 \\
\hline $\mathrm{C} 2$ & $2 / 9$ & $1 / 4$ & $2 / 7$ & 1.222 & 1.250 & 1.286 & 0.605 & 0.640 & 0.669 & 0.081 & 0.088 & 0.093 & 0.087 \\
\hline C4 & $1 / 4$ & $2 / 7$ & $1 / 3$ & 1.250 & 1.286 & 1.333 & 0.454 & 0.498 & 0.536 & 0.061 & 0.068 & 0.075 & 0.068 \\
\hline C6 & $2 / 7$ & $1 / 3$ & $2 / 5$ & 1.286 & 1.333 & 1.400 & 0.324 & 0.373 & 0.417 & 0.044 & 0.051 & 0.058 & 0.051 \\
\hline & & & & & & SUM & 7.160 & 7.311 & 7.440 & & & & \\
\hline
\end{tabular}

The Extended Rough Matrix is arranged by adding antiideal and ideal solutions to the matrix. This matrix is shown in Table 10 and depends on the type of criteria. In this study, all criteria are beneficial, so equations (16) and (17) are applied.

Equation (19) (all criteria are beneficial) is applied to the Extended Rough Matrix to obtain the Rough Normalized Matrix in the following way:

$$
\left[t_{11}^{L}, t_{11}^{U}\right]=\left[\frac{v_{11}^{L}}{v_{\text {id }}^{U}}, \frac{v_{11}^{U}}{v_{\text {id }}^{L}}\right]=\left[\frac{7.72}{8,68}, \frac{8.68}{8.68}\right]=[0.89,1.00] .
$$

Table 11 indicates the Rough Normalized Matrix.
By multiplying (equation (21)) the rough weights of the factors by the rough normalized values, the rough weighted matrix is calculated and presented in Table 12 .

$$
\begin{aligned}
{\left[e_{11}^{L}, e_{11}^{U}\right] } & =\left[t_{11}^{L} \times w_{1}^{L}, t_{11}^{U} \times w_{1}^{U}\right]=[0.89 \times 0.143,1.00 \times 0.143] \\
& =[0.128,0.143] .
\end{aligned}
$$

Using equations (22)-(29), the results of the Rough MARCOS method are obtained and shown in Table 13. The results are obtained using the following computation.

$\mathrm{RN}(Z)$ is computed by equation (22).

$$
\left[z_{1}^{L}, z_{1}^{U}\right]=\left[\begin{array}{c}
0.13+0.12+0.13+0.08+0.11+0.05+0.11+0.12+0.06 \\
0.14+0.13+0.14+0.08+0.11+0.06+0.12+0.13+0.07
\end{array}\right]=[0.887,0.972]
$$


TABLE 8: Evaluation of companies for transporting dangerous goods by all five experts.

\begin{tabular}{|c|c|c|c|c|c|c|c|c|c|c|c|c|c|c|c|c|c|c|c|}
\hline E1 & $\mathrm{C} 1$ & $\mathrm{C} 2$ & $\mathrm{C} 3$ & $\mathrm{C} 4$ & C5 & C6 & $\mathrm{C} 7$ & $\mathrm{C} 8$ & C9 & E2 & $\mathrm{C} 1$ & $\mathrm{C} 2$ & C3 & $\mathrm{C} 4$ & C5 & C6 & C7 & $\mathrm{C} 8$ & C9 \\
\hline TC1 & 9 & 9 & 9 & 7 & 9 & 5 & 7 & 7 & 9 & TC1 & 9 & 9 & 7 & 7 & 9 & 9 & 9 & 9 & 9 \\
\hline TC2 & 3 & 3 & 5 & 3 & 9 & 5 & 5 & 5 & 9 & TC2 & 9 & 9 & 7 & 5 & 9 & 5 & 9 & 9 & 9 \\
\hline TC3 & 9 & 9 & 7 & 7 & 7 & 5 & 7 & 7 & 9 & TC3 & 8 & 9 & 7 & 4 & 6 & 5 & 7 & 5 & 8 \\
\hline TC4 & 9 & 7 & 9 & 7 & 9 & 7 & 9 & 7 & 9 & TC4 & 9 & 9 & 7 & 7 & 9 & 7 & 9 & 9 & 9 \\
\hline TC5 & 7 & 7 & 7 & 5 & 7 & 5 & 7 & 7 & 9 & TC5 & 8 & 9 & 7 & 7 & 9 & 7 & 8 & 7 & 8 \\
\hline TC6 & 7 & 7 & 5 & 5 & 5 & 5 & 7 & 5 & 7 & TC6 & 8 & 9 & 7 & 7 & 9 & 7 & 8 & 7 & 8 \\
\hline TC7 & 5 & 5 & 7 & 5 & 5 & 5 & 7 & 7 & 7 & TC7 & 7 & 9 & 5 & 4 & 7 & 5 & 5 & 5 & 5 \\
\hline TC8 & 3 & 1 & 5 & 3 & 5 & 5 & 3 & 5 & 7 & TC8 & 7 & 9 & 7 & 5 & 7 & 5 & 6 & 6 & 6 \\
\hline ТC9 & 3 & 5 & 3 & 3 & 3 & 3 & 3 & 3 & 5 & TC9 & 3 & 9 & 3 & 3 & 1 & 2 & 3 & 3 & 1 \\
\hline TC10 & 5 & 3 & 7 & 5 & 7 & 3 & 5 & 7 & 7 & TC10 & 8 & 9 & 7 & 7 & 7 & 2 & 6 & 6 & 9 \\
\hline $\mathrm{TC} 11$ & 7 & 7 & 7 & 5 & 7 & 5 & 7 & 7 & 9 & TC11 & 8 & 9 & 7 & 7 & 9 & 7 & 7 & 7 & 9 \\
\hline E3 & $\mathrm{C} 1$ & $\mathrm{C} 2$ & C3 & $\mathrm{C} 4$ & C5 & C6 & C7 & C8 & $\mathrm{C} 9$ & E4 & $\mathrm{C} 1$ & $\mathrm{C} 2$ & C3 & $\mathrm{C} 4$ & C5 & C6 & C7 & $\mathrm{C} 8$ & C9 \\
\hline TC1 & 7 & 7 & 7 & 7 & 9 & 7 & 9 & 9 & 9 & TC1 & 9 & 9 & 7 & 7 & 9 & 7 & 9 & 9 & 9 \\
\hline TC2 & 5 & 5 & 5 & 5 & 7 & 7 & 5 & 3 & 9 & TC2 & 9 & 9 & 7 & 5 & 9 & 5 & 9 & 9 & 9 \\
\hline TC3 & 3 & 3 & 7 & 7 & 5 & 5 & 7 & 7 & 7 & TC3 & 8 & 9 & 7 & 4 & 6 & 5 & 7 & 5 & 8 \\
\hline TC4 & 7 & 9 & 7 & 9 & 9 & 7 & 9 & 9 & 7 & TC4 & 9 & 9 & 7 & 7 & 9 & 7 & 9 & 9 & 9 \\
\hline TC5 & 7 & 7 & 7 & 7 & 7 & 7 & 7 & 7 & 7 & TC5 & 8 & 9 & 7 & 7 & 9 & 7 & 8 & 7 & 8 \\
\hline TC6 & 5 & 7 & 5 & 5 & 5 & 5 & 5 & 5 & 7 & TC6 & 8 & 9 & 7 & 7 & 9 & 7 & 8 & 7 & 8 \\
\hline TC7 & 7 & 7 & 7 & 9 & 9 & 7 & 9 & 7 & 7 & TC7 & 7 & 9 & 5 & 4 & 7 & 5 & 5 & 5 & 5 \\
\hline TC8 & 3 & 5 & 3 & 3 & 3 & 3 & 3 & 3 & 3 & TC8 & 7 & 9 & 7 & 5 & 7 & 5 & 6 & 6 & 6 \\
\hline TC9 & 3 & 5 & 3 & 1 & 1 & 1 & 3 & 3 & 5 & TC9 & 3 & 9 & 3 & 3 & 1 & 2 & 3 & 3 & 1 \\
\hline TC10 & 3 & 5 & 3 & 3 & 1 & 3 & 3 & 3 & 5 & TC10 & 8 & 9 & 7 & 7 & 7 & 2 & 6 & 6 & 9 \\
\hline TC11 & 7 & 9 & 5 & 7 & 7 & 5 & 7 & 7 & 7 & TC11 & 8 & 9 & 7 & 7 & 9 & 7 & 7 & 7 & 9 \\
\hline E5 & $\mathrm{C} 1$ & $\mathrm{C} 2$ & C3 & $\mathrm{C} 4$ & C5 & C6 & C7 & C8 & C9 & & & & & & & & & & \\
\hline TC1 & 9 & 9 & 7 & 7 & 9 & 9 & 9 & 9 & 9 & & & & & & & & & & \\
\hline TC2 & 9 & 9 & 7 & 5 & 9 & 5 & 9 & 9 & 9 & & & & & & & & & & \\
\hline TC3 & 8 & 9 & 7 & 4 & 6 & 5 & 7 & 5 & 8 & & & & & & & & & & \\
\hline TC4 & 9 & 9 & 7 & 7 & 9 & 7 & 9 & 9 & 9 & & & & & & & & & & \\
\hline TC5 & 8 & 9 & 7 & 7 & 9 & 7 & 8 & 7 & 8 & & & & & & & & & & \\
\hline TC6 & 8 & 9 & 7 & 7 & 9 & 7 & 8 & 7 & 8 & & & & & & & & & & \\
\hline TC7 & 7 & 9 & 5 & 4 & 7 & 5 & 5 & 5 & 5 & & & & & & & & & & \\
\hline TC8 & 7 & 9 & 7 & 5 & 7 & 5 & 6 & 6 & 6 & & & & & & & & & & \\
\hline TC9 & 3 & 9 & 3 & 3 & 1 & 2 & 3 & 3 & 1 & & & & & & & & & & \\
\hline TC10 & 8 & 9 & 7 & 7 & 7 & 2 & 6 & 6 & 9 & & & & & & & & & & \\
\hline TC11 & 8 & 9 & 7 & 7 & 9 & 7 & 7 & 7 & 9 & & & & & & & & & & \\
\hline
\end{tabular}

Rough utility degrees of alternatives $\mathrm{RN}\left(Y_{i}^{-}\right)$and $\mathrm{RN}\left(Y_{i}^{+}\right)$are calculated as

$$
\begin{aligned}
& {\left[y_{1}^{-L}, y_{1}^{-U}\right]=\left[\frac{z_{1}^{L}}{z_{\text {aid }}^{U}}, \frac{z_{1}^{U}}{z_{\text {aid }}^{L}}\right]=\left[\frac{0.887}{0.426}, \frac{0.972}{0.318}\right]=[2.082,3.057],} \\
& {\left[y_{1}^{+L}, y_{1}^{+U}\right]=\left[\frac{z_{1}^{L}}{z_{\text {id }}^{U}}, \frac{z_{1}^{U}}{z_{\text {id }}^{L}}\right]=\left[\frac{0.887}{0.918}, \frac{0.972}{0.901}\right]=[0.901,1.079] .}
\end{aligned}
$$

Rough utility degrees $\left(\mathrm{RN}\left(Y_{i}^{-}\right)\right.$and $\left.\mathrm{RN}\left(Y_{i}^{+}\right)\right)$are converted into crisp $Y_{i}^{-}$and $Y_{i}^{+}$. The utility functions in relation to the anti-ideal $f\left(Y_{i}^{-}\right)$and ideal $f\left(Y_{i}^{+}\right)$solutions are computed by equations (27) and (28), respectively.

$$
\begin{aligned}
f\left(Y_{1}\right) & =\frac{Y_{1}^{+}+Y_{1}^{-}}{1+1-f\left(Y_{1}^{+}\right) / f\left(Y_{1}^{+}\right)+1-f\left(Y_{1}^{-}\right) / f\left(Y_{1}^{-}\right)} \\
& =\frac{0.990+2.570}{1+1-0.772 / 0.772+1-0.278 / 0.278}=0.894,
\end{aligned}
$$

where

$$
\begin{aligned}
& f\left(Y_{1}^{-}\right)=\frac{Y_{1}^{+}}{Y_{1}^{+}+Y_{1}^{-}}=\frac{0.990}{0.990+2.570}=0.278, \\
& f\left(Y_{1}^{+}\right)=\frac{Y_{1}^{-}}{Y_{1}^{+}+Y_{1}^{-}}=\frac{2.570}{0.990+2.570}=0.772 .
\end{aligned}
$$

When it comes to the results of evaluating the companies, it can be noticed that $\mathrm{A} 1$ and $\mathrm{A} 4$ show the best performance, while A8 and A9 are in the last position. Transportation company denoted as alternative A1 has the highest value of 0.894 , while transportation company marked as A4 has very close value to the best alternative (0.888). Other alternatives have smaller values and should improve their performances. The worst-ranked transportation company is A9 with a value of 0.381 .

5.3. Sensitivity and Comparative Analysis. In this section of the paper, an extensive analysis of the stability of the developed Fuzzy-Rough MCDM model has been created through three phases. The first phase involves changing the values of the weight coefficients through 30 different scenarios (Figure 4) in which the weights of the three most 
TABle 9: Rough Decision Matrix.

\begin{tabular}{|c|c|c|c|c|c|c|c|c|c|c|c|c|c|c|c|c|c|c|}
\hline & \multicolumn{2}{|c|}{$\mathrm{C} 1$} & \multicolumn{2}{|c|}{$\mathrm{C} 2$} & \multicolumn{2}{|c|}{ C3 } & \multicolumn{2}{|c|}{ C4 } & \multicolumn{2}{|c|}{ C5 } & \multicolumn{2}{|c|}{ C6 } & \multicolumn{2}{|c|}{ C7 } & \multicolumn{2}{|c|}{ C8 } & \multicolumn{2}{|c|}{ C9 } \\
\hline A1 & 7.72 & 8.68 & 7.72 & 8.68 & 7.08 & 7.72 & 7.00 & 7.00 & 9.00 & 9.00 & 6.49 & 8.28 & 7.72 & 8.68 & 7.72 & 8.68 & 8.28 & 8.92 \\
\hline A2 & 3.80 & 6.33 & 3.80 & 6.33 & 5.08 & 5.72 & 3.72 & 4.68 & 7.72 & 8.68 & 5.32 & 6.28 & 5.16 & 6.44 & 3.80 & 6.33 & 9.00 & 9.00 \\
\hline A3 & 5.12 & 7.95 & 5.60 & 8.40 & 5.56 & 6.84 & 4.63 & 6.23 & 5.75 & 6.64 & 4.28 & 4.92 & 6.28 & & 4.49 & & 6.48 & 8.21 \\
\hline A4 & 7.72 & 8.68 & 7.72 & 8.68 & 7.08 & 7.72 & 7.08 & 7.72 & 9.00 & 9.00 & 6.28 & 6.92 & 8.28 & 8.92 & 6.88 & 8.66 & 6.88 & 8.66 \\
\hline A5 & 7.16 & 7.64 & 7.32 & 8.28 & 6.28 & 6.92 & 5.72 & 6.68 & 7.32 & 8.28 & 4.88 & 6.66 & 6.33 & 7.60 & 5.56 & 6.84 & 6.48 & 8.21 \\
\hline A6 & 6.28 & 6.92 & 7.00 & 7.00 & 5.32 & 6.28 & 5.08 & 5.72 & 5.08 & 5.72 & 4.30 & 5.70 & 5.72 & 6.68 & 4.28 & 4.92 & 6.30 & 7.70 \\
\hline A7 & 5.72 & 6.68 & 5.93 & 8.0 & 5.32 & 6.2 & 4.48 & 6.49 & 6.30 & 7.70 & 5.08 & 5.72 & 5.34 & 7. & 4.49 & 6.28 & 5.32 & 6.28 \\
\hline A8 & 3.93 & 6.07 & 3.99 & 7.56 & 4.49 & 6.28 & 3.72 & 4.68 & 4.88 & 6.66 & 4.28 & 4.92 & 3.77 & 5.37 & 3.77 & 5.37 & 4.48 & 6.21 \\
\hline A9 & 3.08 & 3.72 & 5.64 & 7.56 & 3.08 & 3.72 & 2.30 & 3.70 & 1.32 & 2.28 & 1.75 & 2.64 & 3.00 & 3.00 & 3.00 & 3.00 & 1.93 & 4.07 \\
\hline A 10 & 4.65 & 6.96 & 4.81 & 7.64 & 4.88 & 6.6 & 4.49 & 6.28 & 4.04 & 6. & 2.36 & 2.84 & 4.33 & 5.60 & 4.00 & 5. & 5.93 & 8.07 \\
\hline A11 & 6.33 & 7.60 & 6.88 & 8.66 & 5.72 & 6.68 & 5.72 & 6.68 & 6.49 & 8.28 & 4.49 & 6.28 & 6.28 & 6.92 & 5.56 & 6.84 & 6.88 & 8.66 \\
\hline
\end{tabular}

TABle 10: Extended Rough Decision Matrix.

\begin{tabular}{|c|c|c|c|c|c|c|c|c|c|c|c|c|c|c|c|c|c|c|}
\hline \multirow[b]{2}{*}{ AID } & \multicolumn{2}{|c|}{$\mathrm{C} 1$} & \multicolumn{2}{|c|}{$\mathrm{C} 2$} & \multicolumn{2}{|c|}{ C3 } & \multicolumn{2}{|c|}{ C4 } & \multicolumn{2}{|c|}{ C5 } & \multicolumn{2}{|c|}{ C6 } & \multicolumn{2}{|c|}{ C7 } & \multicolumn{2}{|c|}{ C8 } & \multicolumn{2}{|c|}{ C9 } \\
\hline & 3.08 & 3.72 & 3.80 & 6.33 & 3.08 & 3.72 & 2.30 & 3.70 & 1.32 & 2.28 & 1.75 & 2.64 & 3 & 3 & 3 & 3 & 1.93 & 4.07 \\
\hline A1 & 7.72 & 8.68 & 7.72 & 8.68 & 7.08 & 7.72 & 7.00 & 7.00 & 9.00 & 9.00 & 6.49 & 8.28 & 7.72 & 8.68 & 7.72 & 8.68 & 8.28 & 8.92 \\
\hline A2 & 3.80 & 6.33 & 3.80 & 6.33 & 5.08 & 5.72 & 3.72 & 4.68 & 7.72 & 8.68 & 5.32 & 6.28 & 5.16 & 6.44 & 3.80 & 6.33 & 9.00 & 9.00 \\
\hline A3 & 5.12 & 7.95 & 5.60 & 8.40 & 5.56 & 6.84 & 4.63 & 6.23 & 5.75 & 6.64 & 4.28 & 4.92 & 6.28 & 6.92 & 4.49 & 6.28 & 6.48 & 8.21 \\
\hline A4 & 7.72 & 8.68 & 7.72 & 8.68 & 7.08 & 7.72 & 7.08 & 7.72 & 9.00 & 9.00 & 6.28 & 6.92 & 8.28 & 8.92 & 6.88 & 8.66 & 6.88 & 8.66 \\
\hline A5 & 7.16 & 7.64 & 7.32 & 8.28 & 6.28 & 6.92 & 5.72 & 6.68 & 7.32 & 8.28 & 4.88 & 6.66 & 6.33 & 7.60 & 5.56 & 6.84 & 6.48 & 8.21 \\
\hline A6 & 6.28 & 6.92 & 7.00 & 7.00 & 5.32 & 6.28 & 5.08 & 5.72 & 5.08 & 5.72 & 4.30 & 5.70 & 5.72 & 6.68 & 4.28 & 4.92 & 6.30 & 7.70 \\
\hline A7 & 5.72 & 6.68 & 5.93 & 8.07 & 5.32 & 6.28 & 4.48 & 6.49 & 6.30 & 7.70 & 5.08 & 5.72 & 5.34 & 7.12 & 4.49 & 6.28 & 5.32 & 6.28 \\
\hline A8 & 3.93 & 6.07 & 3.99 & 7.56 & 4.49 & 6.28 & 3.72 & 4.68 & 4.88 & 6.66 & 4.28 & 4.92 & 3.77 & 5.37 & 3.77 & 5.37 & 4.48 & 6.21 \\
\hline A9 & 3.08 & 3.72 & 5.64 & 7.56 & 3.08 & 3.72 & 2.30 & 3.70 & 1.32 & 2.28 & 1.75 & 2.64 & 3.00 & 3.00 & 3.00 & 3.00 & 1.93 & 4.07 \\
\hline A10 & 4.65 & 6.96 & 4.81 & 7.64 & 4.88 & 6.66 & 4.49 & 6.28 & 4.04 & 6.58 & 2.36 & 2.84 & 4.33 & 5.60 & 4.00 & 5.93 & 5.93 & 8.07 \\
\hline A11 & 6.33 & 7.60 & 6.88 & 8.66 & 5.72 & 6.68 & 5.72 & 6.68 & 6.49 & 8.28 & 4.49 & 6.28 & 6.28 & 6.92 & 5.56 & 6.84 & 6.88 & 8.66 \\
\hline ID & 7.72 & 8.68 & 7.72 & 8.68 & 7.08 & 7.72 & 7.08 & 7.72 & 9.00 & 9.00 & 6.49 & 8.28 & 8.28 & 8.92 & 7.72 & 8.68 & 9.00 & 9.00 \\
\hline
\end{tabular}

TABle 11: Rough Normalized Matrix.

\begin{tabular}{llllllllllllllllllllll}
\hline & \multicolumn{4}{c}{ C1 } & \multicolumn{3}{c}{ C2 } & \multicolumn{3}{c}{ C3 } & \multicolumn{3}{c}{ C4 } & \multicolumn{3}{c}{ C5 } & \multicolumn{3}{c}{ C6 } & \multicolumn{3}{c}{ C7 } & \multicolumn{2}{c}{ C8 } \\
\hline AID & 0.36 & 0.43 & 0.44 & 0.73 & 0.40 & 0.48 & 0.30 & 0.48 & 0.15 & 0.25 & 0.21 & 0.32 & 0.34 & 0.34 & 0.35 & 0.35 & 0.21 & 0.45 \\
A1 & 0.89 & 1.00 & 0.89 & 1.00 & 0.92 & 1.00 & 0.91 & 0.91 & 1.00 & 1.00 & 0.78 & 1.00 & 0.87 & 0.97 & 0.89 & 1.00 & 0.92 & 0.99 \\
A2 & 0.44 & 0.73 & 0.44 & 0.73 & 0.66 & 0.74 & 0.48 & 0.61 & 0.86 & 0.96 & 0.64 & 0.76 & 0.58 & 0.72 & 0.44 & 0.73 & 1.00 & 1.00 \\
A3 & 0.59 & 0.92 & 0.65 & 0.97 & 0.72 & 0.89 & 0.60 & 0.81 & 0.64 & 0.74 & 0.52 & 0.59 & 0.70 & 0.78 & 0.52 & 0.72 & 0.72 & 0.91 \\
A4 & 0.89 & 1.00 & 0.89 & 1.00 & 0.92 & 1.00 & 0.92 & 1.00 & 1.00 & 1.00 & 0.76 & 0.84 & 0.93 & 1.00 & 0.79 & 1.00 & 0.76 & 0.96 \\
A5 & 0.83 & 0.88 & 0.84 & 0.95 & 0.81 & 0.90 & 0.74 & 0.87 & 0.81 & 0.92 & 0.59 & 0.80 & 0.71 & 0.85 & 0.64 & 0.79 & 0.72 & 0.91 \\
A6 & 0.72 & 0.80 & 0.81 & 0.81 & 0.69 & 0.81 & 0.66 & 0.74 & 0.56 & 0.64 & 0.52 & 0.69 & 0.64 & 0.75 & 0.49 & 0.57 & 0.70 & 0.86 \\
A7 & 0.66 & 0.77 & 0.68 & 0.93 & 0.69 & 0.81 & 0.58 & 0.84 & 0.70 & 0.86 & 0.61 & 0.69 & 0.60 & 0.80 & 0.52 & 0.72 & 0.59 & 0.70 \\
A8 & 0.45 & 0.70 & 0.46 & 0.87 & 0.58 & 0.81 & 0.48 & 0.61 & 0.54 & 0.74 & 0.52 & 0.59 & 0.42 & 0.60 & 0.43 & 0.62 & 0.50 & 0.69 \\
A9 & 0.36 & 0.43 & 0.65 & 0.87 & 0.40 & 0.48 & 0.30 & 0.48 & 0.15 & 0.25 & 0.21 & 0.32 & 0.34 & 0.34 & 0.35 & 0.35 & 0.21 & 0.45 \\
A10 & 0.54 & 0.80 & 0.55 & 0.88 & 0.63 & 0.86 & 0.58 & 0.81 & 0.45 & 0.73 & 0.29 & 0.34 & 0.49 & 0.63 & 0.46 & 0.68 & 0.66 & 0.90 \\
A11 & 0.73 & 0.88 & 0.79 & 1.00 & 0.74 & 0.87 & 0.74 & 0.87 & 0.72 & 0.92 & 0.54 & 0.76 & 0.70 & 0.78 & 0.64 & 0.79 & 0.76 & 0.96 \\
ID & 0.89 & 1.00 & 0.89 & 1.00 & 0.92 & 1.00 & 0.92 & 1.00 & 1.00 & 1.00 & 0.78 & 1.00 & 0.93 & 1.00 & 0.89 & 1.00 & 1.00 & 1.00 \\
\hline
\end{tabular}

TABLE 12: Rough weighted normalized matrix.

\begin{tabular}{lllllllllllllllllllll}
\hline & \multicolumn{3}{c}{ C1 } & \multicolumn{3}{c}{ C2 } & \multicolumn{3}{c}{ C3 } & \multicolumn{3}{c}{ C4 } & \multicolumn{3}{c}{ C5 } & \multicolumn{3}{c}{ C6 } & \multicolumn{4}{c}{ C8 } \\
\hline AID & 0.05 & 0.06 & 0.06 & 0.09 & 0.06 & 0.07 & 0.03 & 0.04 & 0.02 & 0.03 & 0.01 & 0.02 & 0.04 & 0.04 & 0.05 & 0.05 & 0.01 & 0.03 \\
A1 & 0.13 & 0.14 & 0.12 & 0.13 & 0.13 & 0.14 & 0.08 & 0.08 & 0.11 & 0.11 & 0.05 & 0.06 & 0.11 & 0.12 & 0.12 & 0.13 & 0.06 & 0.07 \\
A2 & 0.06 & 0.11 & 0.06 & 0.09 & 0.09 & 0.10 & 0.04 & 0.05 & 0.09 & 0.10 & 0.04 & 0.05 & 0.07 & 0.09 & 0.06 & 0.10 & 0.07 & 0.07 \\
A3 & 0.09 & 0.13 & 0.08 & 0.13 & 0.10 & 0.12 & 0.05 & 0.07 & 0.07 & 0.08 & 0.03 & 0.04 & 0.09 & 0.09 & 0.07 & 0.10 & 0.05 & 0.06 \\
A4 & 0.13 & 0.14 & 0.12 & 0.13 & 0.13 & 0.14 & 0.08 & 0.08 & 0.11 & 0.11 & 0.05 & 0.05 & 0.11 & 0.12 & 0.10 & 0.13 & 0.05 & 0.06 \\
A5 & 0.12 & 0.13 & 0.11 & 0.12 & 0.11 & 0.12 & 0.06 & 0.07 & 0.09 & 0.10 & 0.04 & 0.05 & 0.09 & 0.10 & 0.08 & 0.10 & 0.05 & 0.06 \\
A6 & 0.10 & 0.11 & 0.10 & 0.10 & 0.10 & 0.11 & 0.06 & 0.06 & 0.06 & 0.07 & 0.03 & 0.04 & 0.08 & 0.09 & 0.07 & 0.07 & 0.05 & 0.06 \\
A7 & 0.10 & 0.11 & 0.09 & 0.12 & 0.10 & 0.11 & 0.05 & 0.07 & 0.08 & 0.09 & 0.04 & 0.04 & 0.07 & 0.10 & 0.07 & 0.10 & 0.04 & 0.05 \\
A8 & 0.07 & 0.10 & 0.06 & 0.11 & 0.08 & 0.11 & 0.04 & 0.05 & 0.06 & 0.08 & 0.03 & 0.04 & 0.05 & 0.07 & 0.06 & 0.08 & 0.03 & 0.05 \\
A9 & 0.05 & 0.06 & 0.08 & 0.11 & 0.06 & 0.07 & 0.03 & 0.04 & 0.02 & 0.03 & 0.01 & 0.02 & 0.04 & 0.04 & 0.05 & 0.05 & 0.01 & 0.03 \\
A10 & 0.08 & 0.12 & 0.07 & 0.11 & 0.09 & 0.12 & 0.05 & 0.07 & 0.05 & 0.08 & 0.02 & 0.02 & 0.06 & 0.08 & 0.06 & 0.09 & 0.04 & 0.06 \\
A11 & 0.11 & 0.13 & 0.10 & 0.13 & 0.10 & 0.12 & 0.06 & 0.07 & 0.08 & 0.10 & 0.04 & 0.05 & 0.09 & 0.09 & 0.08 & 0.10 & 0.05 & 0.06 \\
ID & 0.13 & 0.14 & 0.12 & 0.13 & 0.13 & 0.14 & 0.08 & 0.08 & 0.11 & 0.11 & 0.05 & 0.06 & 0.11 & 0.12 & 0.12 & 0.13 & 0.07 & 0.07 \\
\hline
\end{tabular}


TABLE 13: The results of Rough MARCOS.

\begin{tabular}{|c|c|c|c|c|c|c|c|c|c|c|c|c|}
\hline \multirow[b]{2}{*}{ AID } & \multicolumn{2}{|c|}{$\mathrm{RN}(Z)$} & \multicolumn{2}{|c|}{$\mathrm{RN}\left(Y_{i}^{-}\right)$} & \multicolumn{2}{|c|}{$\mathrm{RN}\left(Y_{i}^{-}\right)$} & \multirow[t]{2}{*}{$Y_{i}^{-}$} & \multirow[t]{2}{*}{$Y_{i}^{-}$} & \multirow[t]{2}{*}{$f\left(Y_{i}^{-}\right)$} & \multirow[t]{2}{*}{$f\left(Y_{i}^{+}\right)$} & \multirow[t]{2}{*}{$f\left(Y_{i}\right)$} & \multirow[t]{2}{*}{ Rank } \\
\hline & 0.318 & 0.426 & & & & & & & & & & \\
\hline A1 & 0.887 & 0.972 & 2.082 & 3.057 & 0.901 & 1.079 & 2.57 & 0.99 & 0.278 & 0.722 & 0.894 & 1 \\
\hline $\mathrm{A} 2$ & 0.579 & 0.756 & 1.359 & 2.377 & 0.588 & 0.839 & 1.868 & 0.714 & 0.277 & 0.723 & 0.647 & 8 \\
\hline A3 & 0.623 & 0.814 & 1.462 & 2.56 & 0.632 & 0.903 & 2.011 & 0.768 & 0.276 & 0.724 & 0.694 & 5 \\
\hline A 4 & 0.871 & 0.973 & 2.045 & 3.06 & 0.884 & 1.08 & 2.553 & 0.982 & 0.278 & 0.722 & 0.888 & 2 \\
\hline A5 & 0.746 & 0.864 & 1.751 & 2.717 & 0.757 & 0.959 & 2.234 & 0.858 & 0.277 & 0.723 & 0.774 & 3 \\
\hline A6 & 0.641 & 0.728 & 1.505 & 2.289 & 0.651 & 0.808 & 1.897 & 0.73 & 0.278 & 0.722 & 0.66 & 7 \\
\hline A7 & 0.622 & 0.788 & 1.46 & 2.478 & 0.631 & 0.875 & 1.969 & 0.753 & 0.277 & 0.723 & 0.682 & 6 \\
\hline A8 & 0.479 & 0.695 & 1.124 & 2.186 & 0.486 & 0.771 & 1.655 & 0.629 & 0.275 & 0.725 & 0.569 & 10 \\
\hline A9 & 0.345 & 0.445 & 0.81 & 1.399 & 0.35 & 0.494 & 1.105 & 0.422 & 0.276 & 0.724 & 0.381 & 11 \\
\hline A 10 & 0.514 & 0.743 & 1.207 & 2.336 & 0.522 & 0.825 & 1.772 & 0.674 & 0.276 & 0.724 & 0.611 & 9 \\
\hline A11 & 0.705 & 0.857 & 1.655 & 2.695 & 0.716 & 0.951 & 2.175 & 0.834 & 0.277 & 0.723 & 0.754 & 4 \\
\hline İd & 0.901 & 0.985 & & & & & & & & & & \\
\hline
\end{tabular}

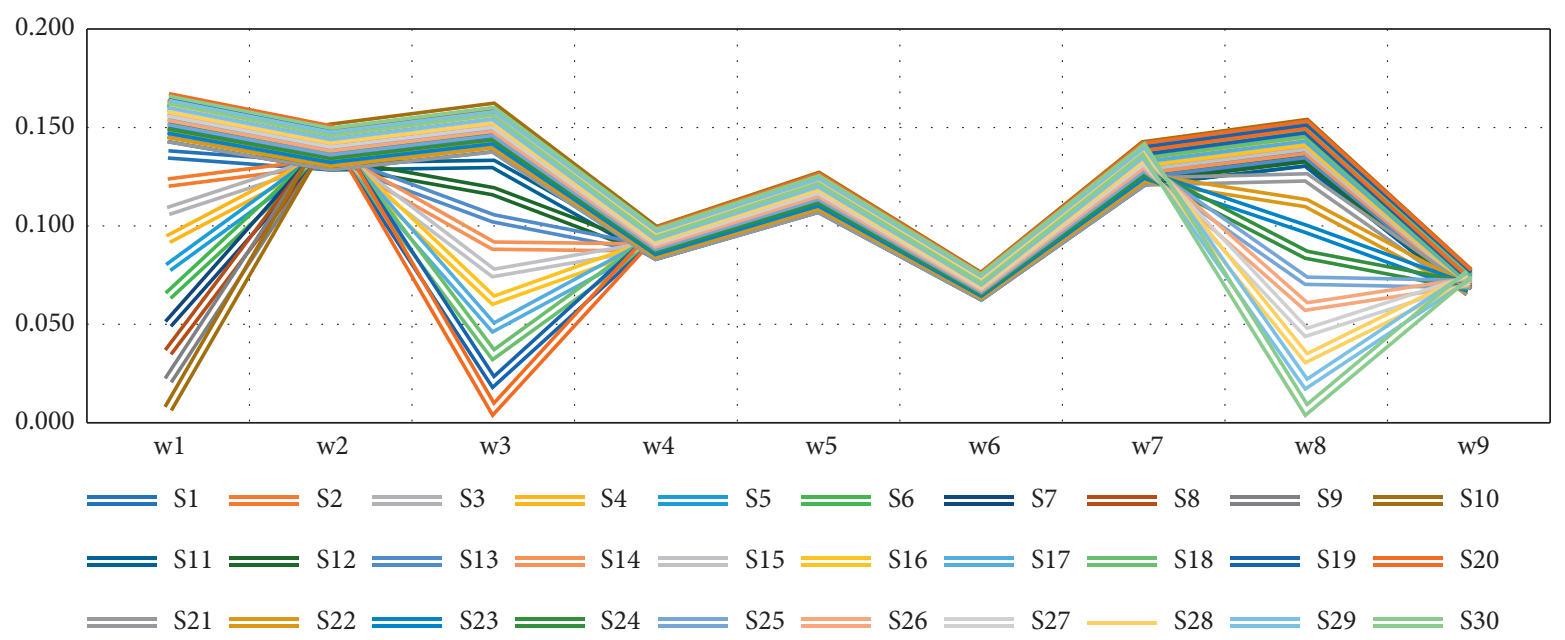

FIgURE 4: New simulated criteria weights used in the sensitivity analysis.

significant criteria are reduced in the range of $5-95 \%$ by applying equation (30) [23]:

$$
W_{n \beta}=\left(1-W_{n \alpha}\right) \frac{W_{\beta}}{\left(1-W_{n}\right)} .
$$

Here, $W_{n \beta}$ represents the corrected value of the criteria, $W_{n \alpha}$ represents the reduced value of the criteria, in this case, criteria $\mathrm{C} 1, \mathrm{C} 3$, and $\mathrm{C} 8, W_{\beta}$ represents the original value of the criterion considered, and $W_{n}$ represents the original value of the criterion whose value is reduced.

In scenarios $\mathrm{S} 1-\mathrm{S} 10$, the weight values of the most significant criterion (C1) were reduced by up to $95 \%$, while, in scenarios S11-S20, the value of the second most significant criterion (C3) was reduced, that is, the third most significant criterion (C8) in scenarios S21-S30.

Figure 5 shows the results of the sensitivity analysis through 30 newly formed scenarios in which there were no significant changes in terms of the ranks of companies for the transport of dangerous goods. The only changes in the ranks of the alternatives occurred in scenarios S7, S8, S9, and S10 when the weights of the most significant criterion $\mathrm{C} 1$ were reduced by 65 , 75,85 , and $95 \%$, respectively. The change of ranks implies the replacement of the positions of alternatives A2 and A6, which occupy the seventh and eighth positions, respectively.
Figure 6 shows the results after applying the sensitivity analysis related to the change in the size of the initial matrix of the Rough MARCOS method. Ten new scenarios have been defined where the sizes of the initial matrix are changed in such a way that the worst-ranked alternative is removed from the initial matrix. In Figure 6, it can also be seen that the values of all alternatives are shown through the scenarios, as well as their ranks. Based on the given components, it follows that the size of the initial rough matrix does not play any role in the final results. It means that all alternatives retain their initial ranks from the original IMF SWARA-Rough MARCOS model. Finally, in the third part of this analysis, the obtained results were compared with several other MCDM methods in a rough form: Rough MABAC [24], Rough TOPSIS [25], Rough WASPAS [26], Rough ARAS [27], Rough SAW [28], Rough COPRAS [29], and Rough CoCoSo [30].

Figure 7 shows the final values of the alternatives in the comparative analysis since there was no change in the rankings. It means that the results from the original IMF SWARA-Rough MARCOS model are fully correlated with the results of the comparative analysis. When it comes to the Rough MARCOS method, the values of the alternatives range from 0.381 to 0.894 , while the situation is much different with the Rough MABAC, and the values range from -0.434 to 


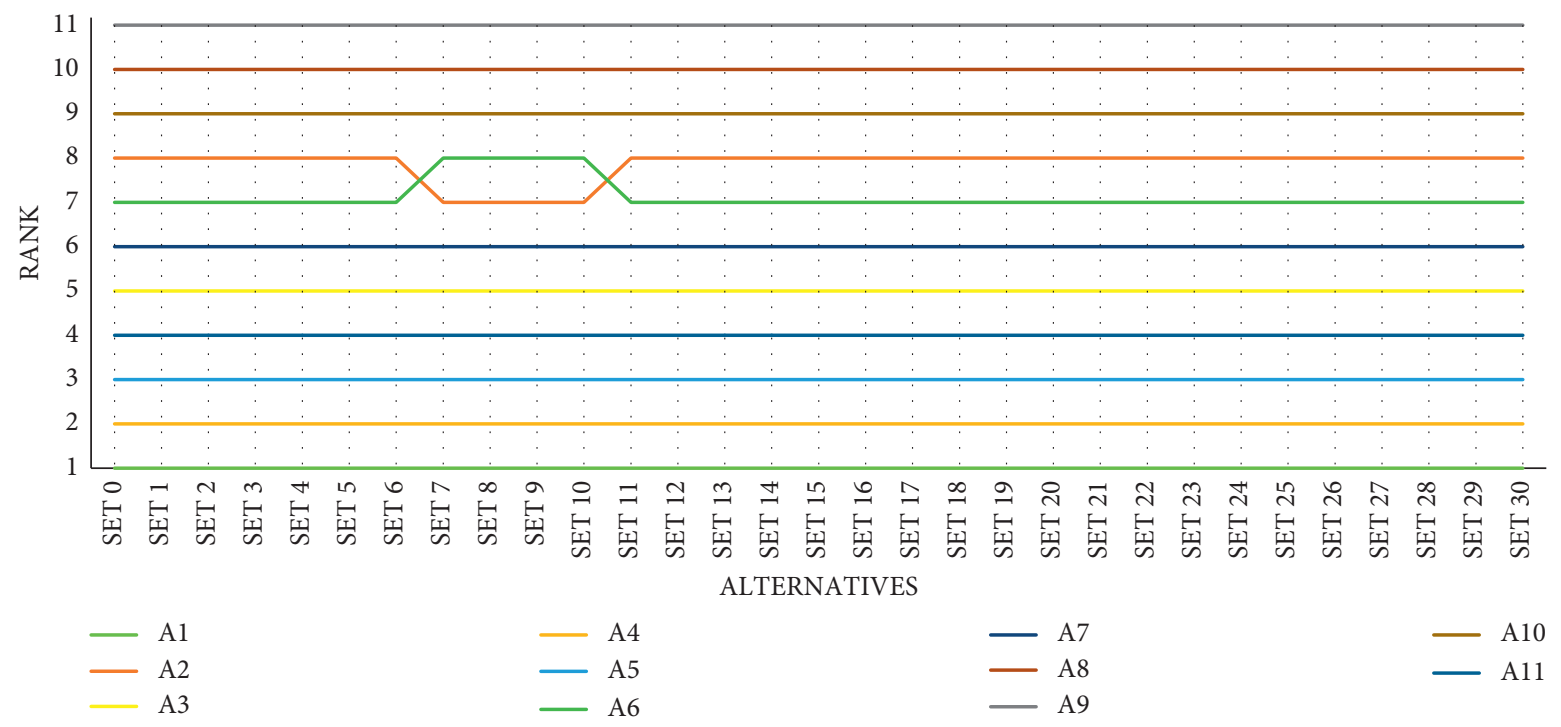

FIgURE 5: Sensitivity analysis with 30 new scenarios.

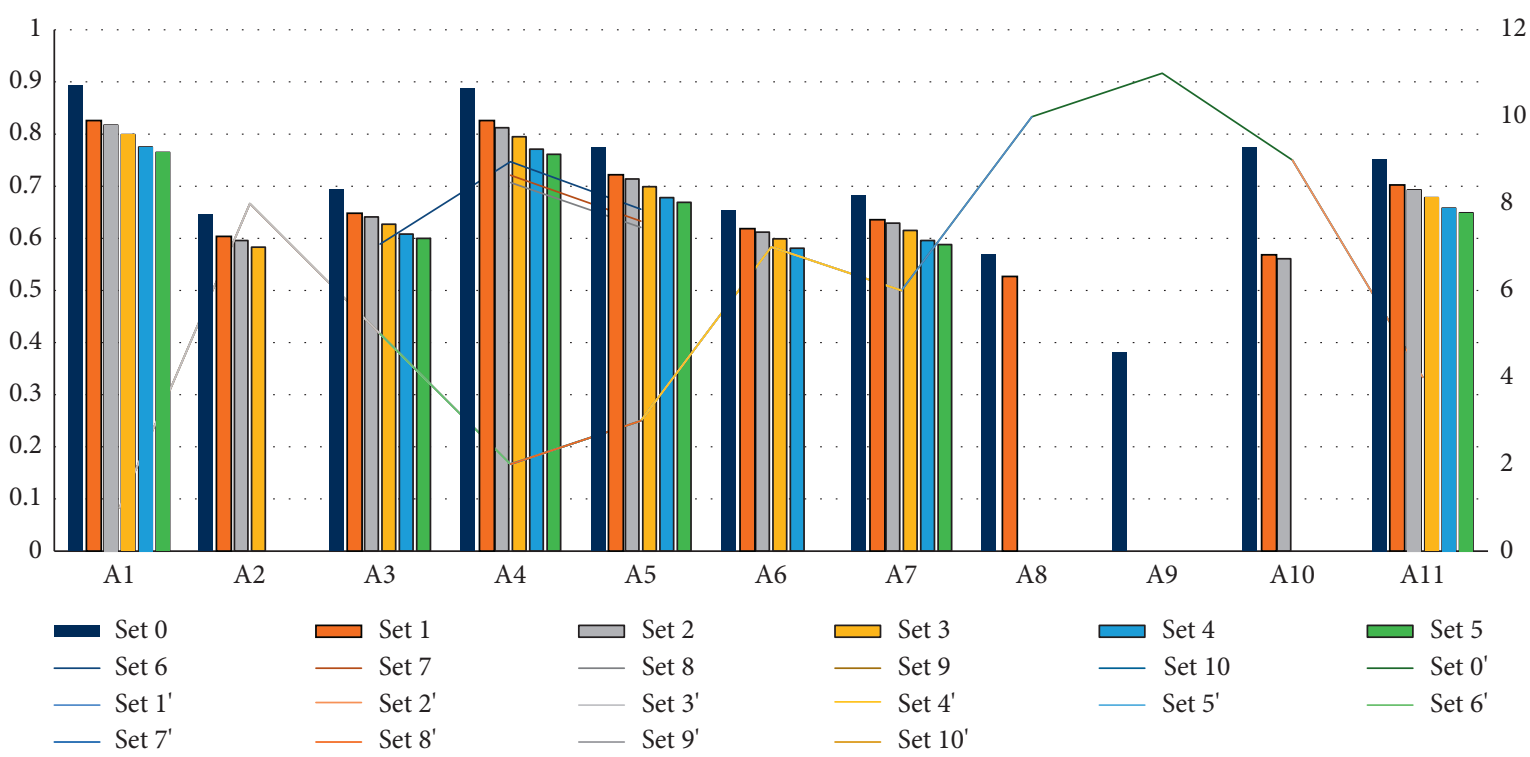

FIgURE 6: Results after resizing the Rough MARCOS initial matrix.

0.344. Further, the values range from 0.219 to 0.858 with Rough TOPSIS, from 0.408 to 0.985 with Rough WASPAS, from 0.438 to 1.028 with Rough ARAS, from 0.418 to 0.979 with Rough SAW, from 0.050 to 0.120 with Rough COPRAS, and from 2.434 to 7.494 with Rough CoCoSo.

The practical usefulness of this developed model is reflected in the possibility of its application to any multicriteria decision-making problem. Thus, it is possible to set up any realistic case study involving uncertainties and arrive at an optimal solution from a set of variant options. When it comes to the case study in this research, its usefulness refers to the possibility of complete insight into the efficiency of the work of companies for the transport of dangerous goods from the aspect of the control body. 


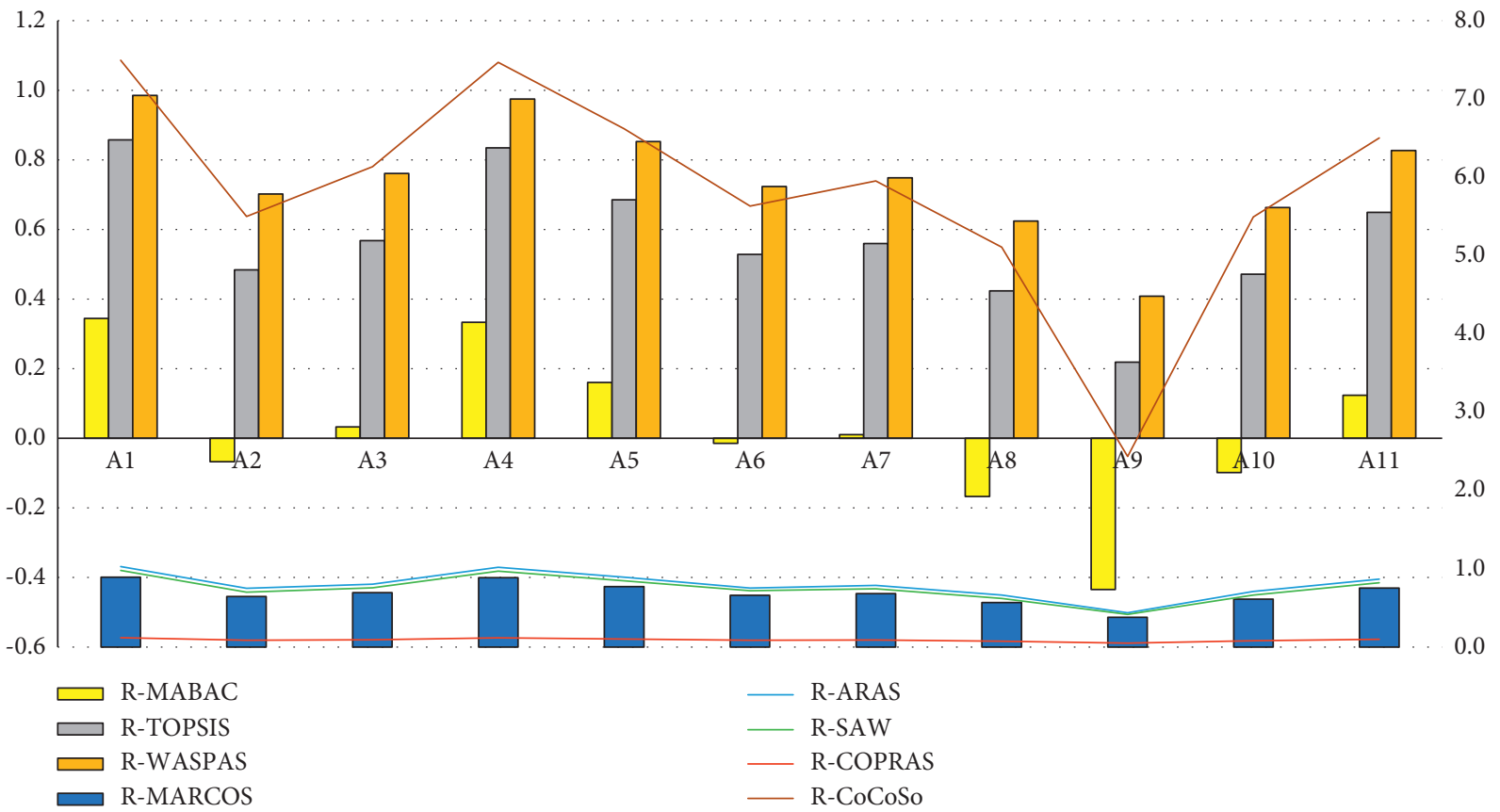

FIGURE 7: Alternative values in comparative Rough MCDM analysis.

\section{Conclusion}

In this paper, a study related to the evaluation of the performance of companies for transporting dangerous goods in the territory of the Republic of Serbia has been carried out. The evaluation was performed for 11 companies based on nine criteria of different structures, which include engineering, legal, technical, technological, and organizational aspects. The results obtained show that the most significant criteria are as follows: dangerous goods classified and permitted under ADR (C1) with a value of 0.143 , prescribed documents in the transport unit (C3) with a value of 0.138 , and the equipment in the transport unit (C8) with a value of 0.131 , while C6, vehicle load control, is ranked the worst with value 0.064 . When it comes to the results of evaluating the companies, it can be noticed that A1 and A4 show the best performance, while A8 and A9 are in the last position. Transportation company denoted as alternative Al has the highest value of 0.894 , while transportation company marked as A4 has very close value to the best alternative $(0.888)$. Other alternatives have smaller values and should improve their performances. The worst-ranked transportation company is A9 with a value of 0.381 . The extensive sensitivity analysis and comparative analysis confirmed the stability of the original improved fuzzy SWARA-Rough MARCOS model. Taking into account such results, managers in companies for transport of dangerous goods can create a set of measures for improving their position of the market. Also, thanks to these obtained results, they can use benchmarking techniques to make their business better and more efficient.

One of the most important contributions that can be pointed out is the development of the original improved fuzzy SWARA-Rough MARCOS model for determining the quantitative values of the performance of companies for transporting dangerous goods. In addition, through the development of such a model, the overall literature has been enriched since the applicability of this model is extremely wide and covers all areas that consider multicriteria problems.

Limitations of research can be represented as participation of only five experts for assessment of performances of companies for transport of dangerous good and consideration of companies in the territory of one narrow geographical area only. Also, nonconsideration of the historical data and previous assessment of these companies can be one of the limitations. Further research can be conducted through the application of this model to determine the performance of companies transporting dangerous goods in a wider geographical area. In addition, it is possible to consider different groups of evaluation criteria and form comparative analyses. Using historical data for assessment and integration with DEA or some other approaches can be one way of future research [19].

\section{Data Availability}

The data used to support the findings of this study are included within this article. However, the reader may contact the corresponding author for more details on the data.

\section{Disclosure}

The results shown in this paper are part of the research project "Improvement of innovative solutions in the function of traffic and transport development" by the Department of Transport of the Faculty of Technical Sciences in Novi Sad, University of Novi Sad, Republic of Serbia. 


\section{Conflicts of Interest}

The authors declare no conflicts of interest.

\section{References}

[1] G. Tepić, S. Sremac, S. Morača, B. Lalić, M. Kostelac, and V. Stojković, "Accidents in facilities for storing hazardous materials," Operational Research in Engineering Sciences: Theory and Applications, vol. 2, no. 2, pp. 24-39, 2019.

[2] S. Sremac, N. Ziramov, I. T. Tanackov, Ž., S. Stević, and B. Ristić, "Ammonia-risk distribution by logistic subsystems and type of consequence," Burns, vol. 46, no. 2, pp. 360-369, 2020.

[3] V. Lukovac, L. Tomić, L. Tomić, and P. Gladovic, "Using the process function method to assess the organizational level in dangerous goods transportation," Operational Research in Engineering Sciences: Theory and Applications, vol. 2, no. 3, pp. 26-39, 2019.

[4] S. Sremac, Ž. Stević, D. Pamučar, M. Arsić, and B. Matić, "Evaluation of a third-party logistics (3PL) provider using a rough SWARA-WASPAS model based on a new rough dombi agregator," Symmetry, vol. 10, no. 8, p. 305, 2018.

[5] J. Janno and O. Koppel, "Human factor as the main operational risk in dangerous goods transportation chain," Business Logistics in Modern Management, 2017.

[6] O. Khomenko, M. Kononenko, M. Kononenko, and I. Myronova, "Ecological and technological aspects of iron-ore underground mining," Mining of mineral deposits, vol. 11, no. 2, pp. 59-67, 2017.

[7] D. Zlatanovic, L. Pezo, A. Sedmak, and S. Kirin, "Importance of on-time decision making in energy sector based on perspectives: case study new Stavalj project," Thermal Science, vol. 21, no. 5, pp. 1925-1935, 2017.

[8] S. Hashemkhani Zolfani, R. Maknoon, and E. K. Zavadskas, "An introduction to prospective multiple attribute decision making (PMADM)," Technological and Economic Development of Economy, vol. 22, no. 2, pp. 309-326, 2016.

[9] S. H. Zolfani, A. E. Torkayesh, and R. Bazrafshan, "Visionbased weighting system (VIWES) in prospective MADM," Operational Research in Engineering Sciences: Theory and Applications, vol. 4, no. 2, pp. 140-150, 2021.

[10] J. Flodén and J. Woxenius, "A stakeholder analysis of actors and networks for land transport of dangerous goods," Research in Transportation Business \& Management, vol. 41, Article ID 100629, 2021.

[11] A. Barylka and M. Chmielinski, "Innovative technologies supporting the safety of the transport of dangerous goods," Modern Engineering, vol. 3, pp. 113-124, 2020.

[12] M. Noureddine, M. Ristic, and M. Ristic, "Route planning for hazardous materials transportation: multi-criteria decisionmaking approach," Decision making: Applications in Management and Engineering, vol. 2, no. 1, pp. 66-84, 2019.

[13] D. Pamučar, S. Sremac, Ż. Stević, G. Ćirović, and D. Tomić, "New multi-criteria LNN WASPAS model for evaluating the work of advisors in the transport of hazardous goods," Neural Computing \& Applications, vol. 31, no. 9, pp. 5045-5068, 2019.

[14] H. Ebrahimi and M. Tadic, "Optimization of dangerous goods transport in urban zone," Decision Making: Applications in Management and Engineering, vol. 1, no. 2, pp. 131-152, 2018.

[15] S. Sremac and M. Matijašević, Transport of Dangerous Goods (Transport Opasne Robe - in Serbian), University of Novi Sad, Faculty of Technical Sciences, Novi Sad, Serbia, 2021.
[16] E. Durmić, Ž. Stević, P. Chatterjee, M. Vasiljević, and M. Tomašević, "Sustainable supplier selection using combined FUCOM-Rough SAW model," Reports in mechanical engineering, vol. 1, no. 1, pp. 34-43, 2020.

[17] I. Đalić, J. Ateljević, Ž. Stević, and S. Terzić, “An integrated swot-fuzzy piprecia model for analysis of competitiveness in order to improve logistics performances," Facta Universitatis - Series: Mechanical Engineering, vol. 18, no. 3, pp. 439-451, 2020.

[18] R. R. Yager, “On generalized Bonferroni mean operators for multi-criteria aggregation," International Journal of Approximate Reasoning, vol. 50, no. 8, pp. 1279-1286, 2009.

[19] D. Pamucar, "Normalized weighted Geometric Dombi Bonferoni Mean Operator with interval grey numbers: application in multicriteria decision making," Reports in Mechanical Engineering, vol. 1, no. 1, pp. 44-52, 2020.

[20] S. Vrtagić, E. Softić, M. Subotić, Ž. Stević, M. Dordevic, and M. Ponjavic, "Ranking road sections based on MCDM model: new improved fuzzy SWARA (IMF SWARA)," Axioms, vol. 10, no. 2, p. 92, 2021.

[21] M. Subotić, V. Radičević, Z. Pavlović, and G. Ćirović, "Development of a new risk assessment methodology for light goods vehicles on two-lane road sections," Symmetry, vol. 13, no. 7, p. 1271, 2021.

[22] ADR, Agreement Concerning the International Carriage of Dangerous Goods by Road - ADR, United Nations, 2021.

[23] M. Bakır, Ş. Akan, and E. Özdemir, "Regional aircraft selection with fuzzy PIPRECIA and fuzzy MARCOS: a case study of the Turkish airline industry," Facta Universitatis - Series: Mechanical Engineering, vol. 19, no. 3, pp. 423-445, 2021.

[24] H. K. Sharma, J. Roy, S. Kar, and O. Prentkovskis, "Multi criteria evaluation framework for prioritizing Indian railway stations using modified rough ahp-mabac method," Transport and Telecommunication Journal, vol. 19, no. 2, pp. 113-127, 2018.

[25] W. Song, X. Ming, Z. Wu, and B. Zhu, "A rough TOPSIS approach for failure mode and effects analysis in uncertain environments," Quality and Reliability Engineering International, vol. 30, no. 4, pp. 473-486, 2014.

[26] Ž. Stević, D. Pamučar, M. Subotić, J. Antuchevičiene, and E. K. Zavadskas, "The location selection for roundabout construction using Rough BWM-Rough WASPAS approach based on a new Rough Hamy aggregator," Sustainability, vol. 10, no. 8, p. 2817, 2018.

[27] D. Radović, Ž. Stević, D. Pamučar et al., "Measuring performance in transportation companies in developing countries: a novel rough ARAS model," Symmetry, vol. 10, no. 10, p. 434, 2018.

[28] E. K. Zavadskas, Z. Nunić, Ž. Stjepanović, and O. Prentkovskis, "A novel rough range of value method (RROV) for selecting automatically guided vehicles (AGVs)," Studies in Informatics and Control, vol. 27, no. 4, pp. 385-394, 2018.

[29] B. Matić, S. Jovanović, D. K. Das et al., "A new hybrid MCDM model: sustainable supplier selection in a construction company," Symmetry, vol. 11, no. 3, p. 353, 2019.

[30] M. Yazdani, P. Chatterjee, D. Pamucar, and S. Chakraborty, "Development of an integrated decision making model for location selection of logistics centers in the Spanish autonomous communities," Expert Systems with Applications, vol. 148, Article ID 113208, 2020. 